\title{
Can We Beat the Random-Walk Model for the South African Rand-U.S. Dollar and South African Rand-UK Pound Exchange Rates? Evidence from Dynamic Model Averaging
}

\author{
Riané de Bruyn ${ }^{\S}$, Rangan Gupta ${ }^{¥}$ and Reneé van Eyden ${ }^{\S}$ \\ Department of Economics, University of Pretoria, Pretoria, South Africa
}

\begin{abstract}
Traditionally, the literature on forecasting exchange rates with many potential predictors have primarily only accounted for parameter uncertainty using Bayesian Model Averaging (BMA). Though BMA-based models of exchange rates tend to outperform the random walk model, we show that when accounting for model uncertainty over and above parameter uncertainty through the use of Dynamic model Averaging (DMA), the gains relative to the random walk model are even bigger. That is, DMA models outperform not only the random walk model, but also the BMA model of exchange rates. We obtain these results based on fifteen potential predictors used to forecast two South African Rand-based exchange rates. In the process, we also unveil variables, which tends to vary over time, that are good predictors of the Rand-Dollar and Rand-Pound exchange rates at different forecasting horizons.
\end{abstract}

JEL Classification codes: C11, C53, F37, F47

Keywords: Bayesian, state space models, exchange rates, macroeconomic fundamentals, forecasting

\footnotetext{
$¥$ To whom correspondence should be addressed. Department of Economics, University of Pretoria, Pretoria, 0002, South Africa, Email: rangan.gupta@up.ac.za.

${ }^{\S}$ Department of Economics, University of Pretoria, Pretoria, 0002, South Africa.
} 


\section{INTRODUCTION}

Accurately forecasting the exchange rates of any currency remains one of the most debated topics in macroeconomics. Numerous papers have attempted to find a model that could outperform a general random walk model specifically in exchange rate forecasting (Wright, 2008; Tortora 2009). The most popular modelling approach,, especially in emerging market economies, thus far, barring a few exceptions (discussed below), involves the monetary model of exchange rate determination and some extensions of the same based on an vector error correction approach, and the use of atheoretical classical and Bayesian vector autoregressions (see Zita and Gupta, 2008; Botha and Pretorius, 2009; Dua and Ranjan, 2011; Égert, 2011; and de Bruyn et al., forthcoming for detailed literature reviews in this regard). However, three concerns arise when using these models: (1) The coefficients on the predictors, which generally involves real, financial and monetary variables, can change over time. The use of dummy variables to capture possible structural breaks, or the use of recursive methods are not suite to solve this issue, and hence ideally, one needs to build models designed to capture the changing slope parameters of the models; (2) Given that the forecasting literature on exchange rates has used a wide variety of predictors, the number of potential predictors are in general quite large; in the process making the number of models quite large as well. For instance, if the set of models is defined by whether each of the $m$ potential predictors are included or excluded, then we have $2^{m}$ possible models to work with. This would raise substantial statistical problems involved in model selection, which in turn, has resulted in researchers resorting to Bayesian model averaging (BMA) as in Wright (2008) and Tortora (2009); (3) Finally, the model relevant for forecasting can itself potentially change over time due to the change in the set of predictors or with some variables better capable of forecasting during the recessions than the expansions. This makes the situation even more complicated, since with $2^{m}$ models, the number of combinations of models required to be estimated in order to forecast at time $\tau$ is $2^{m \tau}$ to allow for the possibility of different model being applicable at each point in time. Even in relatively simple forecasting exercises, it can be computationally impossible to forecast by simply going through all of these $2^{m \tau}$ combinations.

Against this backdrop, this paper applies the dynamic model averaging (DMA) strategy developed by Raftery et al. (2010), which can also be used for dynamic model selection (DMS) (where a single, but potentially different, model can be used as the forecasting model at each point of time) in forecasting twokey bilateral exchange rate involving the South African Rand. DMA or DMS seems ideally suited for forecasting a variable as volatile as the exchange rate, since they not only allow the forecasting model to change over time, but also the coefficients in each model to evolve over time simultaneously. These two methods involve only standard econometric methods used for state space models, such as the Kalman filter, but via some sensible empirical approximations, achieve vast gains in computational efficiency so as to allow us to apply DMA and DMS despite the computational difficulties discussed above. In an emerging 
market economy like South Africa, which has underwent, and still is going through, constant structural changes, it is important to not only allow for parameter, but also for model uncertainty when forecasting key macroeconomic variables.

We use these methods for forecasting the rand-dollar and rand-pound exchange rates using quarterly South African, US and UK data from 1970:1 up to 1994:4 as the in-sample, and 1995:1-2011:3 as the out-ofsample period. A set of fifteen possible predictors, excluding the lagged dependent variable, is used for each respective exchange rate's forecasting model. The forecasting results are then compared to that of other models nested within the DMA and DMS, and also the random walk, using forecast performance measures such as log predictive likelihood and mean square forecast error (MSFE). To, the best of our knowledge, barring the work by Tortora (2009), who used these methods to forecast the US Dollar relative to the Canadian Dollar and the Japanese Yen, no other existing studies look into forecasting bilateral exchange rates based on a wide set of fundamental variables using DMA and DMS methods. However, Tortora (2009) uses a measurement equation where the model either includes a predictor at all points in time or always excludes it. Even though Tortora (2009) was an improvement over Wright (2008), who used BMA to account for parameter uncertainty, unlike us, it does not allow for the set of predictors to vary over time, and hence, in some sense, model uncertainty is only partially handled in Tortora (2009). Using South Africa as a case study, given our familiarity with its evolution, this paper aims to add to the forecasting literature on exchange rates by being the first paper of its kind to apply DMA and DMS methods. The exchange rate forecasting literature in South Africa covers the monetary model of exchange rate determination and its extensions, non-linear models, small and large-scale (classical and Bayesian) vector autoregressive models, factor models and dynamic stochastic general equilibrium (DSGE) models. Botha and Pretorius (2009) compared various univariate time series models, including the random walk model, to various multivariate time series models based on a set of fundamentals in forecasting the rand-dollar exchange rate. They found that the multivariate models outperformed the univariate models, but not the random walk model for onequarter-ahead forecasts. However, the multivariate models performed better in the longer-run forecasts. In terms of long-run forecasts, similar conclusions were reached by de Bruyn et al., (forthcoming) when they analyzed one-year-ahead forecasts, based on the monetary model estimated using over a century of annual data. Bonga-Bonga (2008), however, showed that a time-varying model for the rand-dollar spot exchange rate, based on forward exchange rates, outperformed the random walk model for one-month-ahead forecasts. These findings were corroborated by Bong-Bonga (2009) when using a smooth transition regression model relating the spot and forward exchange rates. Gupta and Kabundi (2010), when using a small-open economy DSGE model to forecast the nominal effective exchange rate depreciation, shows the ability of such a model to outperform not only classical and Bayesian VARs based on a small set of predictors, but also large-scale factor models and Bayesian VARs relying on 266 macroeconomic time-series. Similar results were obtained by Alpanda et al., (2011) based on a relatively more sophisticated small-open economy DSGE model. The authors found that the DSGE model consistently outperformed the random-walk model in forecasting, the 
depreciation of the nominal rand-dollar exchange rate, and also performed better, in general, than the smallscale VAR and Bayesian VARs, based on a set ten fundamental variables. So overall, exchange rate models developed for South Africa have tended to outperform the random-walk model. In light of this, an obvious question then is: Why do we need another study on forecasting the South African exchange rates? The answer lies in the novelty involved in the DMA and DMS approaches, and their abilities, in turn, to allow for parameter and model uncertainty. More importantly, unlike any of the previous studies on South Africa, our paper allows us to identify the most important predictors out of the fifteen fundamentals used (based on the international and domestic literature), and also observe how their importance might have varied over time; at the same time allowing us to link such variability with economic events in the economy that occurred over the out-of-sample period. This information is of paramount importance to a policy-maker, as it would help in understanding the source of variability in exchange rate movements, and in turn, help in designing appropriate policy measures to reduce the fluctuations in the value of the domestic currency, if required. To put it simply, our approach to exchange rate modeling not only helps us to identify the best models, but also, the best predictors of exchange rate over time.

The rest of the paper is structured as follows: Section 2 provides an outline of the methodology used; section 3 contains the data description and section 4 presents the empirical results and alternative model comparisons in terms of forecasts. Finally, section 5 concludes.

\section{METHODOLOGY}

Time-varying parameter (TVP) models employ state space methods such as the Kalman filter, which is commonly used in empirical macroeconomic research. These types of models however do not allow for the predictors to vary over time (Koop \& Korobilis, 2012). If large sets of predictors are used, TVP models tend to over-fit in-sample and therefore have poor out-of-sample forecasting performance. Even extensions of these models such as the TVP-VAR models suffer from this same limitation (Koop \& Korobilis, 2012). To address these short comings in the TVP models, DMA models present a possible alternative.

Dynamic model averaging (DMA), as the name implies, averages across various models. BMA, which is a specific form of the DMA model, is only used for static linear models with parameter uncertainty. The uncertainty is accounted for by averaging over all the sets of possible explanatory variables that may be included in the models (Raftery et al., 2010). A short fall with the BMA approach is that it is limited to static models only. It was observed that the dynamics of the various models tend to follow a hidden Markov chain which can be incorporated using a recursive updating method such as the Kalman filter (Raftery et al., 2010). 
Using the DMA framework, the BMA can be easily derived by simply excluding any dynamics from the DMA estimates.

To understand the econometric methodology, suppose that we have a set of $K$ models which are characterized by having different subsets of $z_{t}$ as predictors. Denoting these by $z^{(k)}$ for $k=1, \ldots, K$, our set of models can be written as:

$$
\begin{aligned}
& y_{t}=z_{t}^{(k)} \theta_{t}^{(k)}+\varepsilon_{t}^{(k)} \\
& \theta_{t+1}^{(k)}=\theta_{t}^{(k)}+\eta_{t}^{(k)}
\end{aligned}
$$

$\varepsilon_{t}^{(k)}$ is $N\left(0, H_{t}^{(k)}\right)$ and $\eta_{t}^{(k)}$ is $N\left(0, Q_{t}^{(k)}\right)$. Let $L_{t} \in\{1,2, \ldots, K\}$ denote which model applies at each time period, $\Theta_{t}=\left(\theta_{t}^{(1)^{\prime}}, \ldots, \theta_{t}^{(K)^{\prime}}\right)^{\prime}$ and $y^{t}=\left(y_{1}, \ldots, y_{t}\right)$. The fact that we are allowing different models to hold at each point in time and perform model averaging, give rise to the terminology "dynamic model averaging". To be precise, when forecasting time $t$ variables using information through time $t-1$, DMA involves calculating $\operatorname{Pr}\left(L_{t}=k \mid y^{t-1}\right)$ for $k=1, . ., K$, and averaging forecasts across models using these probabilities. DMS involves selecting the single model with the highest value for $\operatorname{Pr}\left(L_{t}=k \mid y^{t-1}\right)$ and using this to forecast. However, there are problems with such a framework, since many of the models can have a large number of parameters, and the computational burden which arises when $K$ is large implies that estimation can take a long time. Thus, a full Bayesian approach to DMA can be quite difficult. Following Koop and Korobilis (2012), in this paper, we use approximations suggested by Raftery et al., (2010). The approximations used by Raftery et al. (2010) involve two parameters, $\lambda$ and $\alpha$, which they refer to as forgetting factors and fix to numbers slightly below one.

To explain the role of these forgetting factors, first consider the standard state space model below for $t=$ 1....T:

$$
\begin{aligned}
& y_{t}=z_{t} \theta_{t}+\varepsilon_{t} \\
& \theta_{t}=\theta_{t-1}+\eta_{t}
\end{aligned}
$$

In our case, $y_{t}$ is the (growth rate of the) exchange rate, $z_{t}=\left[1, x_{t-1}, y_{t-1}, \ldots ., y_{t-p}\right]$ is an $1 \times m$ vector of predictors for the (growth rate of the) exchange rate which also includes an intercept and lags of the dependent variable, $\theta_{t}=\left[f_{t-1}, \beta_{t-1}, \gamma_{t-1}, \ldots, \gamma_{t-p}\right] \quad$ is an $1 \times m$ vector of states, $\varepsilon_{t} \sim N\left(0, H_{t}\right)$ and $\eta_{t} \sim N\left(0, Q_{t}\right)$, with the errors assumed to be mutually independent at all leads and lags. For given values of $H_{t}$ and $Q_{t}$, standard filtering and smoothing results can be used to carry out forecasting.

Kalman filtering begins with the result that 


$$
\theta_{t-1} \mid y^{t-1}: N\left(\hat{\theta}_{t-1}, \sum_{t-1 \mid t-1}\right)
$$

where formulae for $\hat{\theta}_{t-1}$ and $\sum_{t-1 \mid t-1}$ are standard. Note here only that these formulae depend on $H_{t}$ and $Q_{t}$. Then Kalman filtering proceeds using:

$$
\theta_{t} \mid y^{t-1} \sim N\left(\hat{\theta}_{t-1}, \sum_{t \mid t-1}\right)
$$

where

$$
\sum_{t \mid t-1}=\sum_{t-1 \mid t-1}+Q_{t}
$$

Raftery et al. (2010) note that things simplify substantially if this latter equation is replaced by:

$$
\sum_{t \mid t-1}=\frac{1}{\lambda} \sum_{t-1 \mid t-1}
$$

or, equivalently, $Q_{t}=\left(1-\lambda^{-1}\right) \sum_{t-1 \mid t-1}$ where $0<\lambda \leq 1$. Raftery et al. (2010) set $\lambda=0.99$. For quarterly macroeconomic data, this suggests observations five years ago receive approximately $80 \%$ as much weight as last period's observation.

Forecasting in the one model case is then completed by the updating equation:

$$
\theta_{t} \mid y^{t} \sim N\left(\hat{\theta}_{t}, \sum_{t \mid t}\right)
$$

where

$$
\hat{\theta}_{t}=\hat{\theta}_{t-1}+\sum_{t \mid t-1} z_{t}\left(H_{t}+z_{t} \sum_{t \mid t-1} z_{t}^{\prime}\right)^{-1}\left(y_{t}-z_{t} \hat{\theta}_{t-1}\right)
$$

and

$$
\sum_{t \mid t}=\sum_{t \mid t-1}-\sum_{t \mid t-1} z_{t}\left(H_{t}+z_{t} \sum_{t \mid t-1} z_{t}^{\prime}\right)^{-1} z_{t} \sum_{t \mid t-1}
$$

Recursive forecasting is done using the predictive distribution

$$
y_{t} \mid y_{t-1} \sim N\left(z_{t} \hat{\theta}_{t-1}, H_{t}+z_{t} \sum_{t \mid t-1} z_{t}^{\prime}\right) .
$$


The case with many models, (1), uses the previous approximation and an additional one. To understand this, we now switch to the notation for the multiple model case in (3) and let $\Theta_{t}$ denote the vector of all the coefficients. In the standard single model case, Kalman filtering is based on (4), (5) and (7). In the multimodel case, for model $k$, these three equations become:

$$
\begin{aligned}
& \Theta_{t-1 \mid L_{t-1}}=k, y^{t-1} \square N\left(\hat{\theta}_{t-1}^{(k)}, \Sigma_{t-1 \mid t-1}^{(k)}\right) \\
& \Theta_{t \mid L_{t}}=k, y^{t-1} \square N\left(\hat{\theta}_{t-1}^{(k)}, \Sigma_{t \mid t-1}^{(k)}\right) \\
& \Theta_{t \mid L_{t}}=k, y^{t} \square N\left(\hat{\theta}_{t}^{(k)}, \Sigma_{t \mid t}^{(k)}\right),
\end{aligned}
$$

where $\hat{\theta}_{t}^{(k)}, \Sigma_{t \mid t}^{(k)}$ and $\sum_{t \mid t-1}^{(k)}$ are obtained via Kalman filtering in the usual way using (8), (9) and (6), except with $(k)$ superscripts added to denote model $k$.

The previous results were all conditional on $L_{t}=k$, and we need a method for unconditional prediction. In this paper, we follow the suggestion of Raftery et al. (2010) and as used in Koop and Korobilis (2012), involving a forgetting factor for the state equation for the models, $\alpha$, which in turn, is, comparable to the forgetting factor $\lambda$ used with the state equation for the parameters. The derivation of Kalman filtering ideas begins with (4). The analogous result, when doing DMA, is

$$
P\left(\Theta_{t-1}, L_{t-1} \mid y^{t-1}\right)=\sum_{k=1}^{K} P\left(\theta_{t-1}^{(k)} \mid L_{t-1}=k, y^{t-1}\right) \operatorname{Pr}\left(L_{t-1}=k \mid y^{t-1}\right)
$$

where $P\left(\theta_{t-1}^{(k)} \mid L_{t-1}=k, y^{t-1}\right)$ is given by (11). To simplify notation, let $\pi_{t \mid s, l}=\operatorname{Pr}\left(L_{t}=l \mid y^{s}\right)$ and thus, the final term on the right hand side of (14) is $\pi_{t-1 \mid t-1, k \text {. }}$

With,

$$
\pi_{t \mid t-1, k}=\frac{\pi_{t-1 \mid t-1, k}^{\alpha}}{\sum_{l=1}^{K} \pi_{t-l \mid t-1, l}^{\alpha}},
$$

where $0<\alpha \leq 1$ is set to a fixed value slightly less than one and is interpreted in a similar manner to $\lambda$., i.e., if $\alpha=0.99$ forecast performance five years ago receives $80 \%$ as much weight as forecast performance last period (when using quarterly data). Comparable to those of the updating equation in the Kalman filter, we have a model updating equation of: 


$$
\pi_{t \mid t, k}=\frac{\pi_{t \mid t-1, k P k^{(}}\left(y_{t} \mid y^{t-1}\right)}{\sum_{l=1}^{K} \pi_{t \mid t-1, l P l}\left(y_{t} \mid y^{t-1}\right)}
$$

where $p_{l}\left(y_{t} \mid y^{t-1}\right)$ is the predictive density for model $l$, which is the Normal density in (10) with $(l)$ superscripts added and evaluated at $y_{t}$.

Recursive forecasting can be done by averaging over predictive results for every model using $\pi_{t \mid t-1, k}$. So, for instance, DMA point predictions are given by:

$$
E\left(y_{t} \mid y^{t-1}\right)=\sum_{k=1}^{K} \pi_{t \mid t-1, k} z_{t}^{(k)} \hat{\theta}_{t-1}^{(k)}
$$

DMS proceeds by selecting the single model with the highest value for $\pi_{t \mid t-1, k}$ at each point in time and simply using it for forecasting. Note also that, if $\alpha=1$, then $\pi_{t \mid t-1, k}$ is simply proportional to the marginal likelihood using data through time $t-1$, and yields the standard approaches in BMA. If we also set $\lambda=1$, then we obtain BMA using conventional linear forecasting models with no time variation in coefficients. In our forecast comparison exercise, we include BMA in our set of alternative forecasting procedures and implement this by setting $\alpha=\lambda=1$.

The preceding discussion is all conditional on $H_{t}$. Raftery et al. (2010) recommend a simple plug in method where $H_{t}^{(k)}=H^{(k)}$ and is replaced with a consistent estimate. When forecasting (growth rate of the) exchange rate, however, it is likely that the error variance is changing over time. Theoretically, we could use a stochastic volatility or ARCH specification for $H_{t}^{(k)}$. However, this is computationally burdensome, so instead, we follow Koop and Korobilis (2012) and use an Exponentially Weighted Moving Average (EWMA) estimate of $H_{t}^{(k)}$ :

$$
\hat{H}_{t}^{(k)}=\sqrt{(1-\kappa) \sum_{j=1}^{t} \kappa^{j-1}\left(y_{j}-z_{j}^{(k)} \hat{\theta}_{j}^{(k)}\right)^{2}}
$$

where $k$ is called a decay factor and is set to 0.98 as in Koop and Korobilis (2012). The period $t+1$ forecast given data up to time $t$ takes the form. 


$$
\hat{H}_{t+l \mid t}^{(k)}=\kappa \hat{H}_{t \mid t-1}^{(k)}+(1-\kappa)\left(y_{t}-z_{t}^{(k)} \hat{\theta}_{t}^{(k)}\right)^{2}
$$

\section{DATA}

This paper's analysis is based on quarterly data, mostly sourced from the Global Financial Database. The sample period under consideration is from the first quarter of 1970 up to the third quarter of 2011. The outof-sample period ranges from the first quarter of 1995 to the third quarter of 2011 - a normal choice given South Africa's reintegration into the world economy.

Our selection of explanatory variables is mainly informed by Tortora (2009), De Jager (2012), Wright (2008) and Feldkircher (2008), with the nominal rand-dollar and rand-pound exchange rates being the dependent variables. We identified three categories for the deterministic variables, namely real, monetary and financial variables for South Africa, the US and the UK. Based on Coleman et al. (2011), who propose a long-run exchange rate model for a group of African countries where the real price of oil is included as a deterministic variable, we include South Africa's main commodity prices namely that of oil and gold. All variable acronyms, definitions and sources are tabulated in the Data Appendix. In cases where variables as specified by Tortora (2009) proved unavailable, similar variables were used. Tortora (2009) includes the annual growth rate in real income, which was excluded from our analysis, whereas we decided to rely on the output differentials. We did however include additional variables such as M2, M3 and their respective growth rates, as well as the gold price.

The data is kept in the respective home currencies to exclude any exchange rate effects in the movement of these variables. All the variables are obtained in seasonally adjusted form, and if not available in a seasonally adjusted form, seasonal adjustment is carried out using the X-12 approach proposed by the Department of Commerce, US Census Bureau. Variables that are available at higher frequencies than a quarter are averaged out over the respective weeks or months to reach quarterly figures. All variables are calculated as log differences, except for the variables measured in percentage changes (growth rates) or the balance on the current account variable which is expressed as a ratio of GDP. These variables are only differenced as some of the data points are negative and cannot be logged. As the variable names indicate in the Data Appendix, the differencing is done by subtracting the logged foreign data from the logged South African data, and is applicable to all variables in levels.

The Augmented Dickey-Fuller, Dickey-Fuller GLS (Generalized Least Squares) and the Ng-Perron tests were performed on all the constructed variables as discussed above to test for stationarity. In cases where the results are ambiguous, results from the $\mathrm{Ng}$-Perron unit root test take preference due to improved finite- 
sample performance of the test. All of the variables proved to be integrated of order one except for the variables measuring money supply growth as well as the short-term interest rate variable.

Transformations similar to those used by Koop and Korobilis (2012) were applied to the data series, in order to transform all of the variables to be approximately stationary. The different transformation codes and descriptions are listed and defined in the Data Appendix.

\section{EMPIRICAL RESULTS}

The empirical results are divided into two sub-sections. These subsections present results using DMA and DMS in our preferred way, i.e., by setting $\alpha=0.99$ and $\lambda=0.99$, a noninformative prior over the models $\left(\pi_{0 \mid 0, k}=1 / K\right.$ for $\left.k=1, \ldots, K\right)$ and a relatively diffuse prior for the initial state conditions: $\theta_{0}^{(k)} \sim N(0,100)$ for $k=1, \ldots, K$. The first sub-section provides evidence of which variables are good exchange rate predictors from the list of potential variables listed in the Data Appendix. In the second sub-section, we compare the forecast performance of the DMA to a number of alternative forecasting models nested in the DMA, including BMA and the random walk model. The forecasting horizons range from one $(d=1)$ up to four $(d=4)$ quarters. All of the models include an intercept and one lag of the dependent variable, chosen by the Schwarz information criterion. ${ }^{1}$

\subsection{GOOD PREDICTORS FOR EXCHANGE RATES}

One of the largest potential benefits using the DMA framework is that it allows the forecasting model to change over time, i.e. the model parameters may change, as well as the set of predictors. Given the difficulty in explaining exchange rate movements, we include a set of 15 possible predictors (excluding the lag dependent variable) for each exchange rate, hence we have 32768 possible models to choose from.

Let $S_{i z e_{k}}$ be the number of predictors excluding the constant and one lag of the dependent variable, then we can define: $E\left(\right.$ Size $\left._{t}\right)=\sum_{k=1}^{K} \pi_{t \mid t-1, k}$ Size $_{k} \cdot \sum_{k=1}^{K} \pi_{t \mid t-1, k}$ Size $_{k}$ can be interpreted as the expected or average number of predictors used in DMA at time $t$. Figures 1 and 2 depicts this for the Rand-Dollar and Rand-Pound exchange rates, respectively, over the out-of-sample period. From Figures 1 and 2, we observe that for the initial part of the out-of-sample period, no predictors are chosen, suggesting that the constant and first lag are enough to predict the exchange rate. However, after the initial periods, the number of predictors vary between five to

\footnotetext{
${ }^{1}$ Also, experimentation with up to four lags of the dependent variable showed that one lag length leads to the best forecast performance for both the rand-pound and rand-dollar exchange rates.
} 
ten for the different forecast horizons. Interestingly, the number of predictors for both the Rand-based bilateral exchange rates tend to behave similarly. So, between two-thirds and one-third of the predictors end up being excluded in an attempt to achieve parsimony. Clearly, there exists evidence that DMA will shrink forecasts and the way this shrinkage is done also changes over time. However, the figures does not tell us which predictors are important and how they are change over time - this is what we move to next.

Figure 1: Expected number of predictors included in rand-dollar exchange rate models over the out-of-sample period

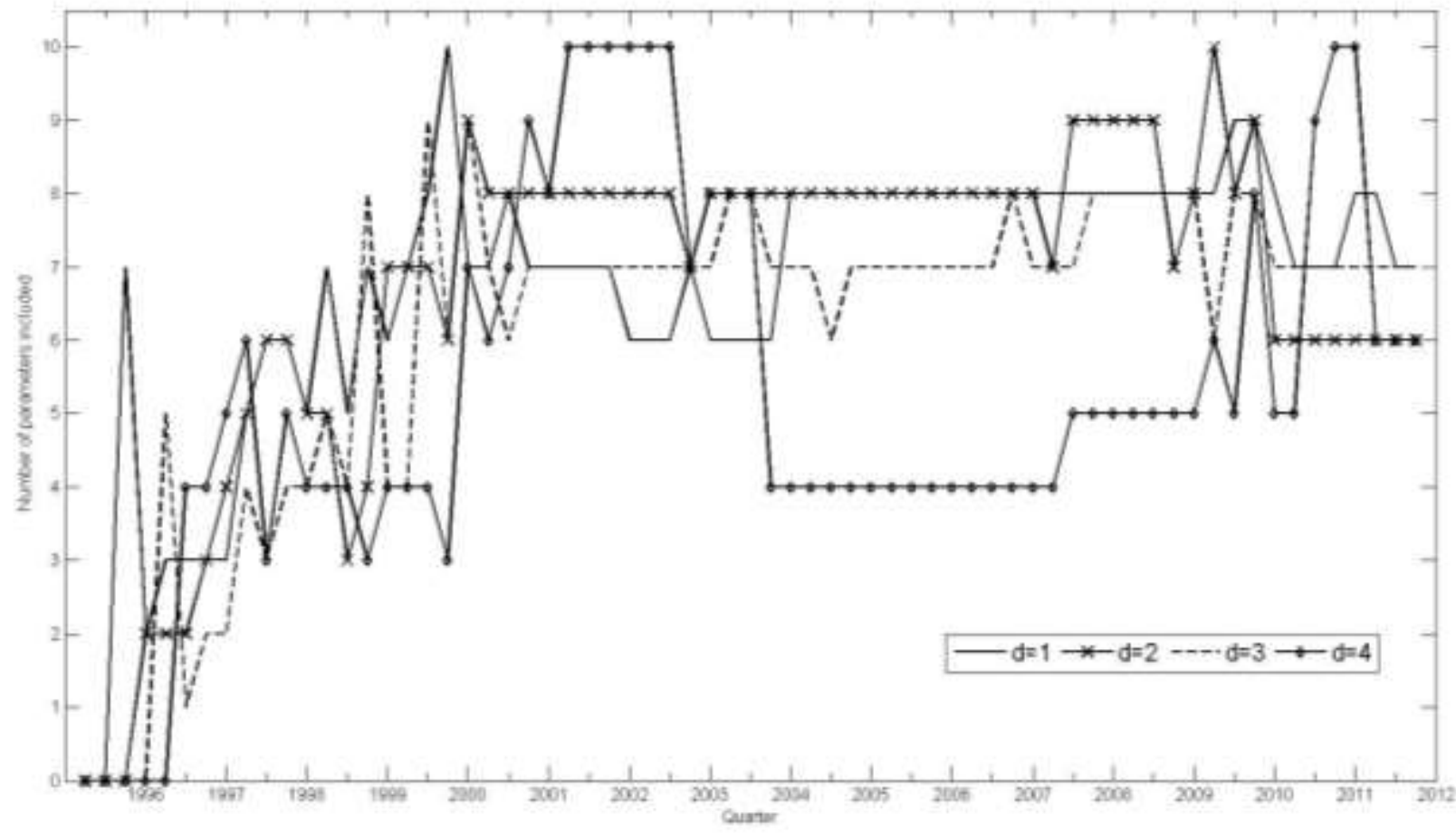

Figure 2: Expected number of predictors included in the rand-pound exchange rate models over the out-ofsample period

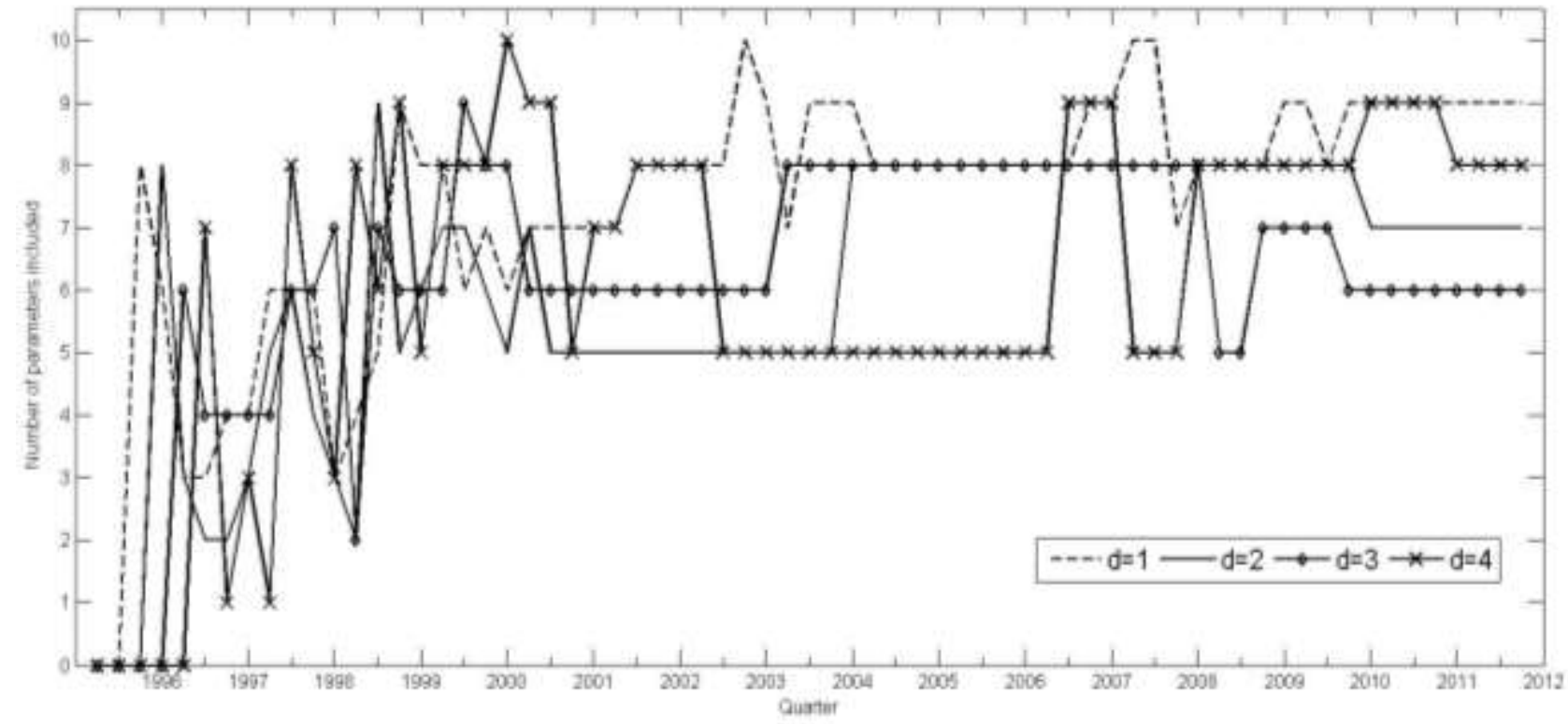


We begin by presenting evidence that, when forecasting exchange rates, the forecasting model is indeed changing over time. When using an average inclusion probability of 0.5 and higher, i.e., selecting the variables that are important on average, the maximum number of predictor variables used in DMA over the out-of-sample period varies between 7 and 8 for the different forecasting horizons of the rand-dollar exchange rate, and between 7 and 9 for the rand-pound exchange rate, excluding the intercept and lagged dependent variable. It is clear from these figures that the DMS is almost always choosing parsimonious models and the weights (posterior inclusion probability) in DMA heavily reflect parsimonious models. Also, for both the exchange rates and for all four forecast horizons, we observe strong evidence of model change, as the set of predictors useful for forecasting is changing over time.

When considering the selection of predictor variables at individual time periods, the number of variables selected in periods post-2000 tends to be significantly lower than the maximum and also remains relatively constant for a number of successive periods. This could potentially be attributed to the change to an inflation targeting policy framework, adopted by the South African Reserve Bank in February 2000. Mtonga (2011) found that a change in monetary policy, such as the implementation of inflation targeting, will have a significant effect on the exchange rate.

The evolution and characteristics of the South African exchange rate system has indeed undergone dramatic changes during the past four decades. A relatively rigid administered system during the early 1970s made way for a managed, floating exchange rate regime. Following the De Kock Commission Report in 1979, measures aiming at a freely floating commercial rand were introduced. However, the socio-political turbulence of the mid-eighties rendered the rand extremely vulnerable to negative foreign sentiment. Balance of payments crises of severe proportions followed the widespread institution of financial and trade sanctions against South Africa. In addition to the debt standstill agreement, exchange control on capital transfers by non-residents was reinstated in the form of the financial rand. General uncertainty and lack of confidence resulted in the largest depreciation of the rand against the US dollar in history (Coleman et al., 2011). The rand lost 50 per cent of its value against the US dollar within one year as a result.

Political reform culminating in the democratic election of the Government of Unity in 1994, paved the way for the normalisation of the country's international financial relations. The financial rand was finally abolished in March 1995 and hardly any exchange control over non-residents was retained. Gradual relaxation of exchange control of residents was introduced from July 1995 onwards. These measures marked the beginning of complete integration of South Africa into the capital markets of the world.

The first quarter of 1995 is taken as the start of the out-of-sample period for our analysis. This out-of-sample period is however not free from external influences impacting the volatility and movement of the rand against all major currencies, notably international events such as the Asian financial crisis of 1997/98 and the 
associated financial contagion which led to a decline in investor confidence in emerging-market economies, including South Africa. The powerful negative shock also sharply reduced the price of oil, which reached a low of about $\$ 11$ per barrel towards the end of 1998. The reduction in oil revenue in turn contributed to the 1998 Russian financial crisis, while other major developing economies like Brazil and Argentina also fell into crisis during the late 1990s.

From the end of 2001 up to the beginning of 2002, the rand depreciated by approximately 20 per cent against the US dollar, but regained its value during 2003 and 2004. This sudden depreciation was found not to be caused by economic fundamentals, but by speculation against the rand and other external factors (de Jager, 2012). The global financial crisis is considered by many to be the worst financial crisis since the Great Depression of the 1930s and resulted in the threat of total collapse of large financial institutions, the bailout of banks by national governments, and downturns in stock markets around the world.

Next, we turn to reporting the main predictors as selected by the DMA analysis for both the rand-dollar and rand-pound exchange rate models. For every forecast horizon, $d=1$ to $d=4$, for the out-of-sample period 1995:1 to 2011:3, we use average posterior inclusion probabilities of 0.5 and higher as selection criteria for inclusion of predictor variables in the exchange rate model for every period. All variables with an average of 0.5 and higher are included in the graphs (figures 3 to 10). Overall, we find evidence of model and parameter variability for both exchange rates over all forecast horizons considered.

The model specifications tested include macroeconomic fundamentals such as the real GDP differential, inflation differential, interest rate differential, difference in long-term bond yield and the differentials of M1, M2 and M3 money supply as well as growth differentials of M1, M2 and M3. In addition, relative current account balances, commodity prices, such as gold and oil, and differentials of stock market prices were tested for inclusion. Whereas the majority of predictors are derived from the standard monetary model of exchange rate determination, stock market activity has grown in importance as predictor for exchange rates movements over the years. Gyntelberg, Loretan, Subhanij and Chan (2009) show that investors' private information about international markets feed through the stock market to changes in exchange rates. Their results show that investors' transactions on the stock exchange of Thailand had more explanatory power than other order flows, in the short and long run (Gyntelberg et al., 2009).

Since South Africa's export market is largely commodity based, and with open trading of commodities on international markets, it is also not unexpected to see the gold price as a significant predictor of the randdollar and rand-pound exchange rates. The rand is sometimes referred to as a commodity currency. Since gold is still one of South Africa's main export commodities, accounting for 10 percent of South Africa's total exports, it is not surprising that the gold price holds significant exchange rate predictive power. 
The oil price variable shows significance together with gold as predictors for both exchange rates. Throop, Laderman and Walsh (1993) refer to a "recycling" of funds between oil-exporting and oil-importing countries. With a high oil price, oil-exporting countries have more funds to invest in oil-importing countries, more specifically developing countries. These countries will then in turn invest in more developed oilimporting countries, who will again lend money to developing countries. This phenomenon has become more prominent in recent years, hence the significance of oil price in determining exchange rates.

The significance of the balance on the current account in explaining exchange rate behaviour is shown by Hooper and Morton (1982) as shifts in the equilibrium real exchange rate through expectations about longterm portfolio balances. This can therefore be seen as an exchange rate risk premium on wealth and asset supplies (Hooper \& Morton, 1982). Differentials on current account balances however did not prove to be a significant variable in explaining exchange rate behaviour in any of the models under consideration here.

Overall the results reveal that selection of the typical monetary model variables, namely the real GDP differential, CPI inflation differential, M3 money supply differential, and to a lesser extent the interest rate differential, are consistently selected across all horizons for both exchange rate models. In addition, either M1 or M2 money supply differentials, or both, were selected for a number of forecast horizons, providing further support for the monetary model specification, given that these aggregates are included in the M3 broad money variables.

Also, three other predictor variables are consistently selected for inclusion across all horizons, for both models. These include the stock market price differential and both commodity prices, gold and oil. It is however striking that the average inclusion probabilities for these variables generally exceed that of the monetary model variables, with average probabilities exceeding 0.7 and 0.8 in a number of instances. It is also obvious from figures 3 to 10 that these variables especially gained prominence in terms of significance from 2000 onwards. On the other hand, real GDP differentials, CPI inflation differentials and M3 money supply differentials have on average a lower average inclusion probability, but the variation in probability values for successive periods is much less over the out-of-sample period.

Figures 3 to 10 contain all variables with average posterior probabilities exceeding 0.5 with the four variables with the highest probabilities included in part (a) and the remainder variables in part (b) of each figure. Results for the rand-dollar exchange rate are presented in figures 3 to 6 and for the rand-pound exchange rate in figures 7 to 10 . 
Figure 3: Rand-dollar: posterior probability of inclusion of predictors, 1-quarter-ahead forecast $(d=1)$

(a)

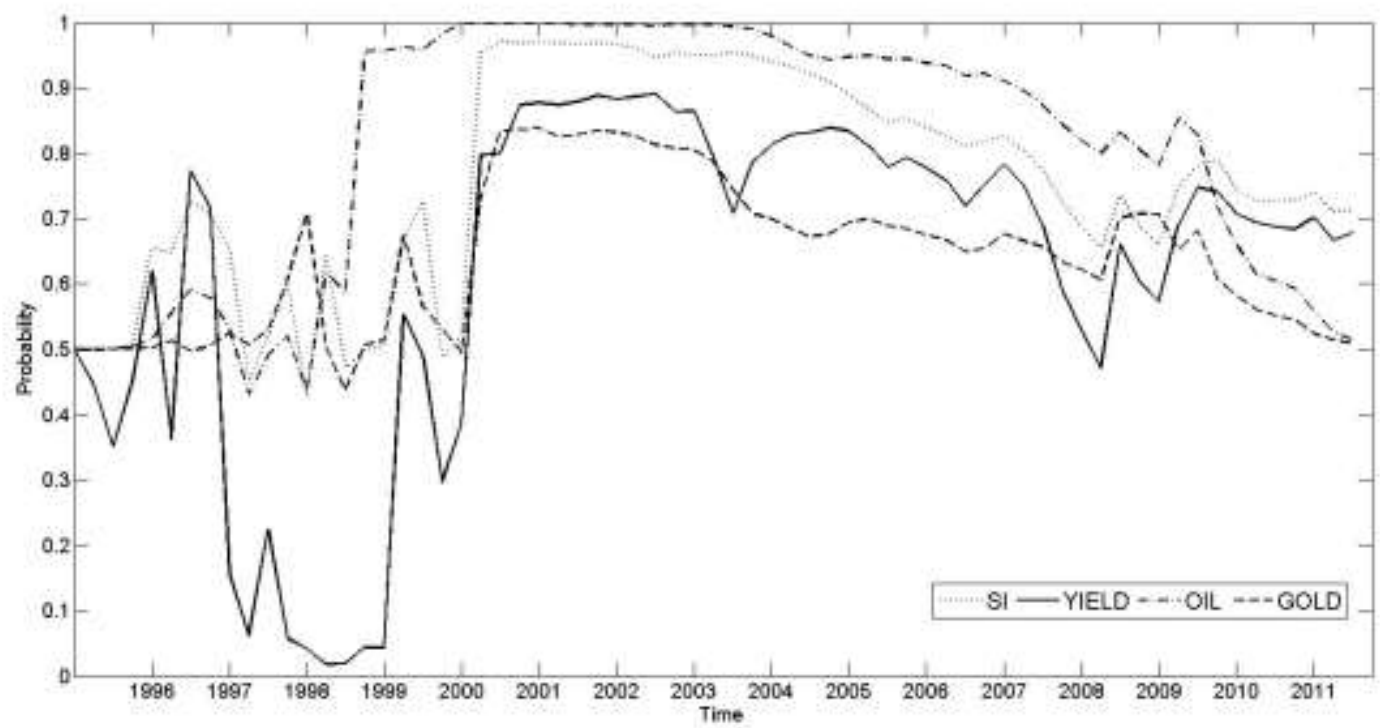

(b)

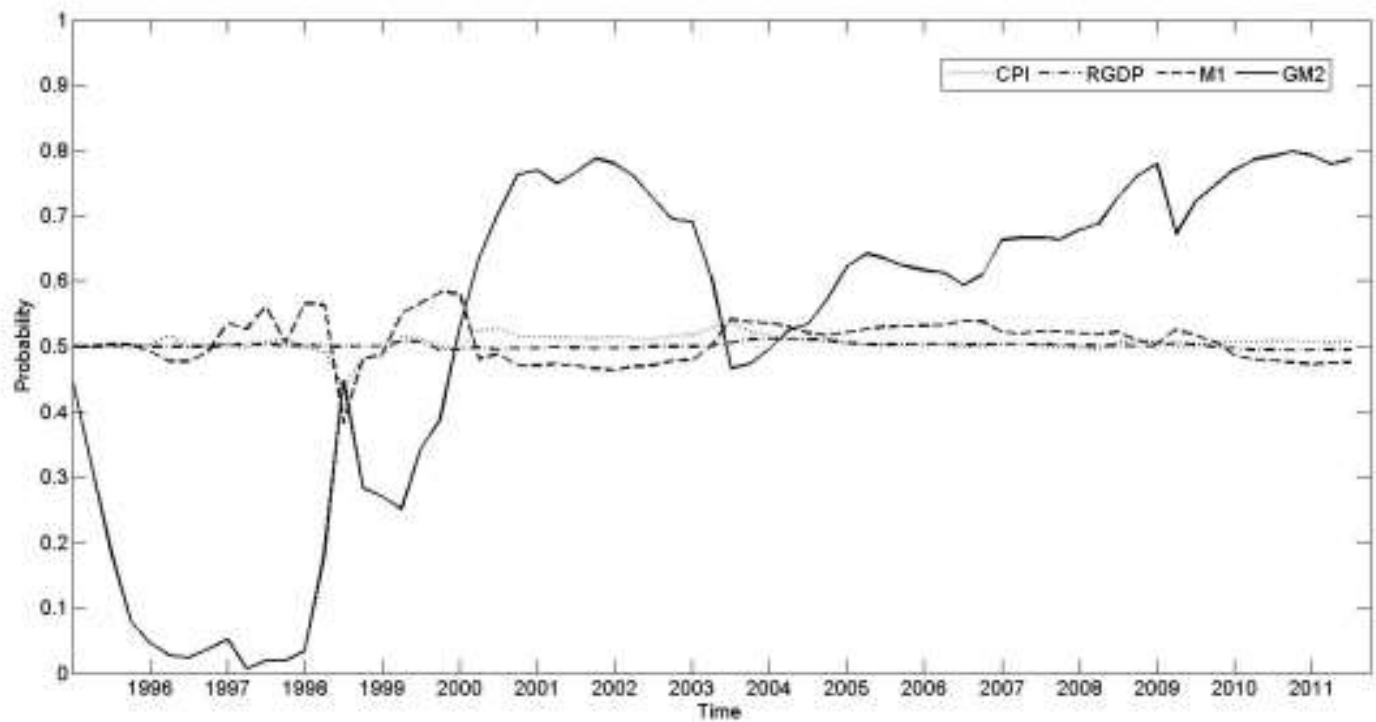

In figure 3 we see that especially after 2001, the stock market index differential (SI), the oil price (OIL), gold price (GOLD) and long-term bond yield (YIELD) are identified as important variables in the 1-quarter-ahead forecast horizon, Over shorter forecast horizons the forecaster may thus look towards stock market and capital market activity as a yard stick for expected exchange rate movements. Real GDP, CPI inflation and M1 money supply differential ( $R G D P, C P I$ and $M I$ respectively) have very stable probabilities with inclusion probabilities exceeding 0.5 by a small margin. 
Figure 4: Rand-dollar: posterior probability of inclusion of predictors, 2-quarter-ahead forecast $(d=2)$

(a)

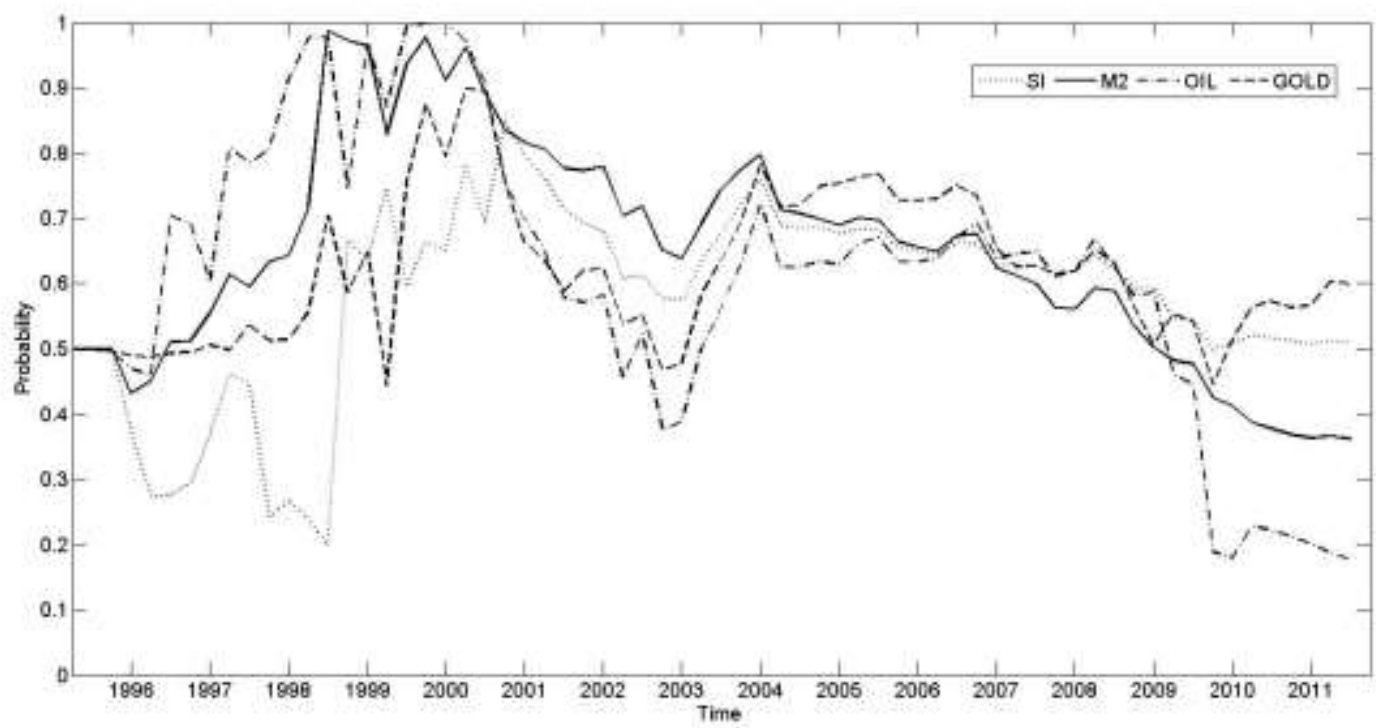

(b)

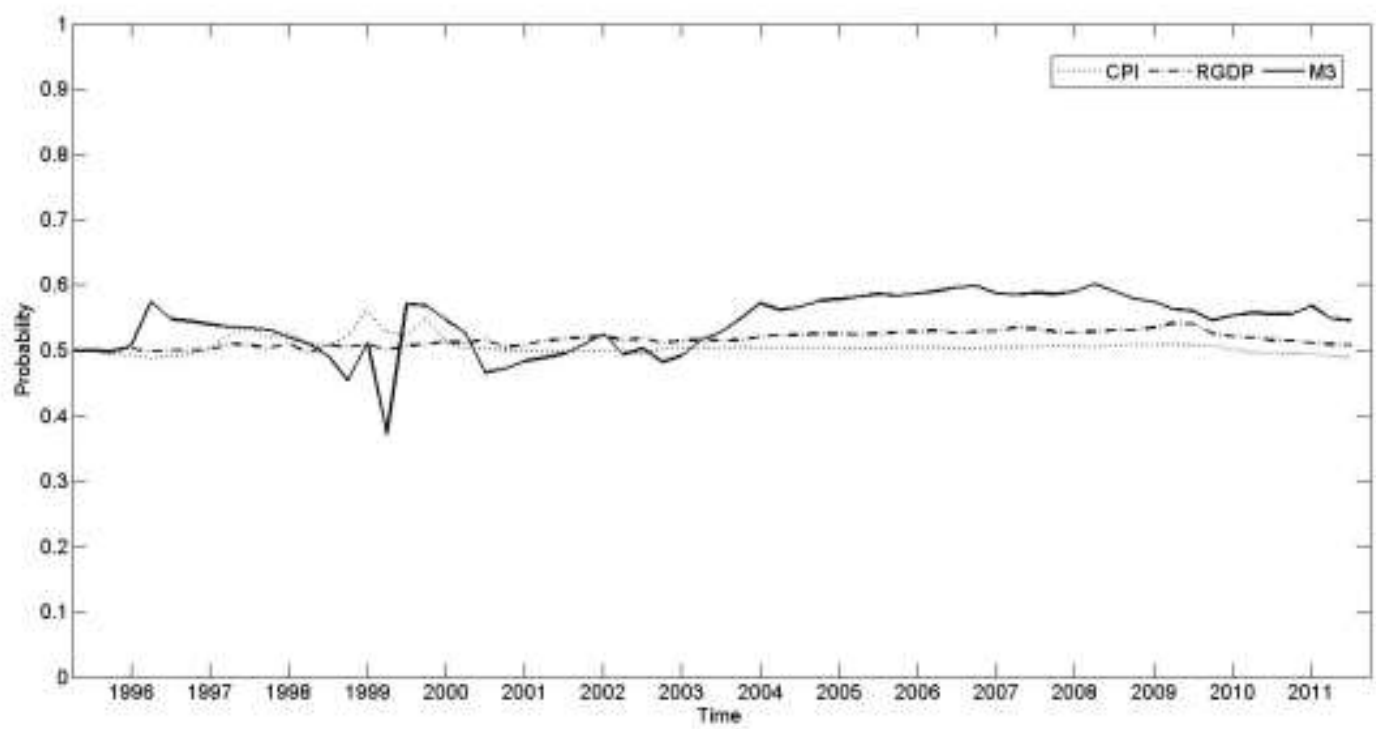

Almost the same hold true for the 2-quarter-ahead forecast horizon, except that M2 money supply ( $M 2$ ) is selected with a high inclusion probability instead of the long-term bond yield. It is noteworthy that surrounding the Russian and various other emerging market crises during the late-nineties, the probability of inclusion of the oil price exceeds 0.9 , while the gold price and stock market price differential reached probabilities of 0.9 during the 2001 currency crisis with the speculative attack on the rand. Once again the real GDP, CPI inflation and M3 money differentials display stable probabilities of inclusion of between 0.5 and 0.6 for the entire period. 
Figure 5: Rand-dollar: posterior probability of inclusion of predictors, 3-quarter-ahead forecast $(d=3)$

(a)

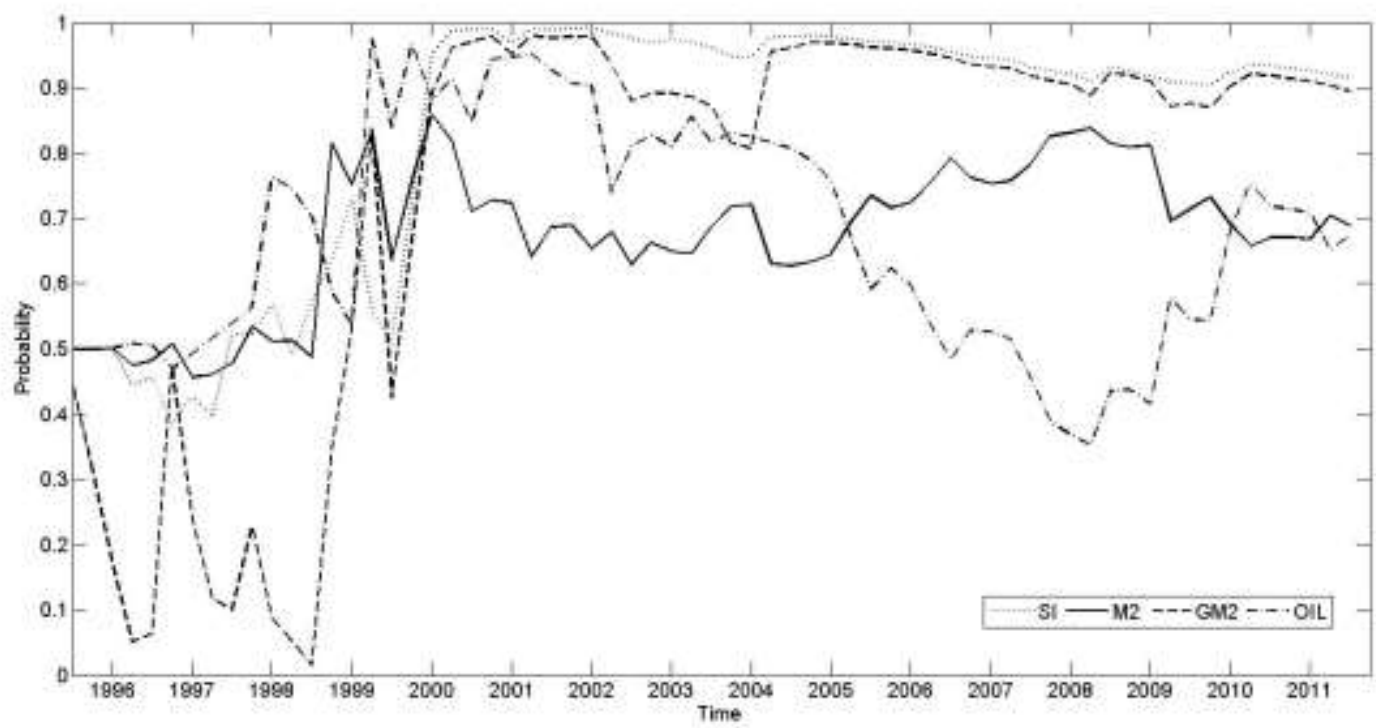

(b)

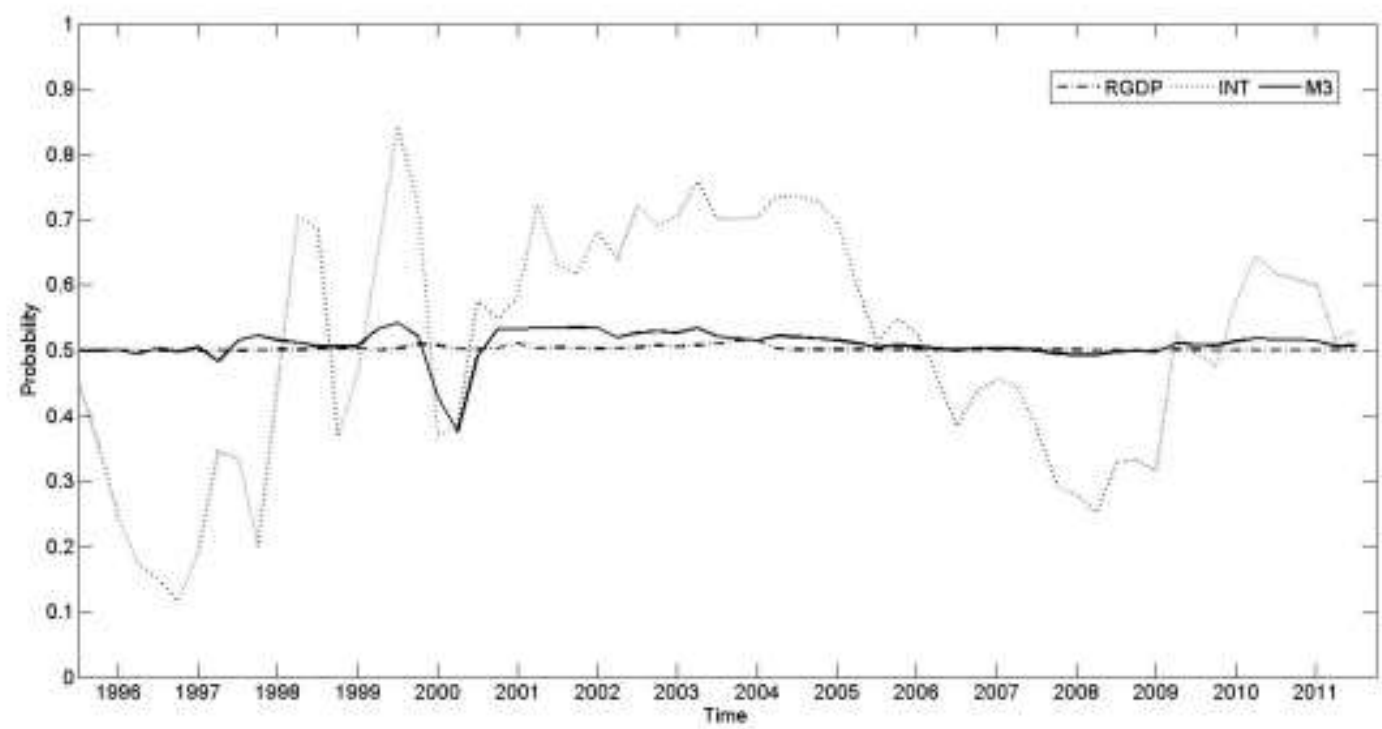

For the 3-quarter-ahead forecast for the rand-dollar exchange rate (figure 5), both the stock market price differential and M2 money growth differential maintain high inclusion probabilities in excess of 0.9 . The oil price is an important variable, but looses significance towards the end of the sample period. The short-term interest rate differential (INT) is selected for this forecast horizon with increased importance in the period from 2000 to 2006, while the real GDP and M3 money supply differentials once again show a stable inclusion probability marginally above 0.5 .

Looking at the rand-dollar rate for a 4-quarter-ahead forecast horizon (figure 6), variables selected include commodity prices, oil and gold, as well as broad and narrow money variables, with probabilities of inclusion, exceeding 0.8 in the post 2001 period. All monetary model variables, with the exception of the interest rate differential, are also selected for inclusion (see figure 6(b)). 
Figure 6: Rand-dollar: posterior probability of inclusion of predictors, 4-quarter-ahead forecast $(d=4)$

(a)

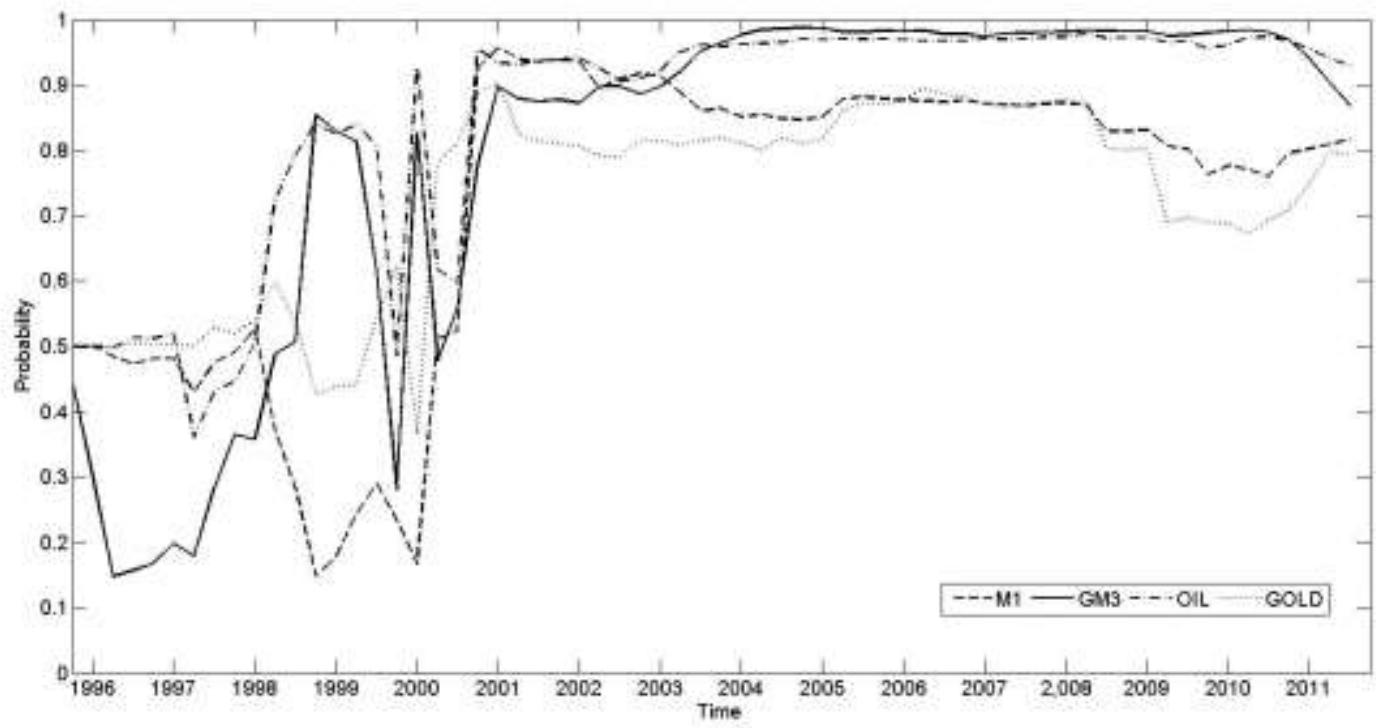

(b)

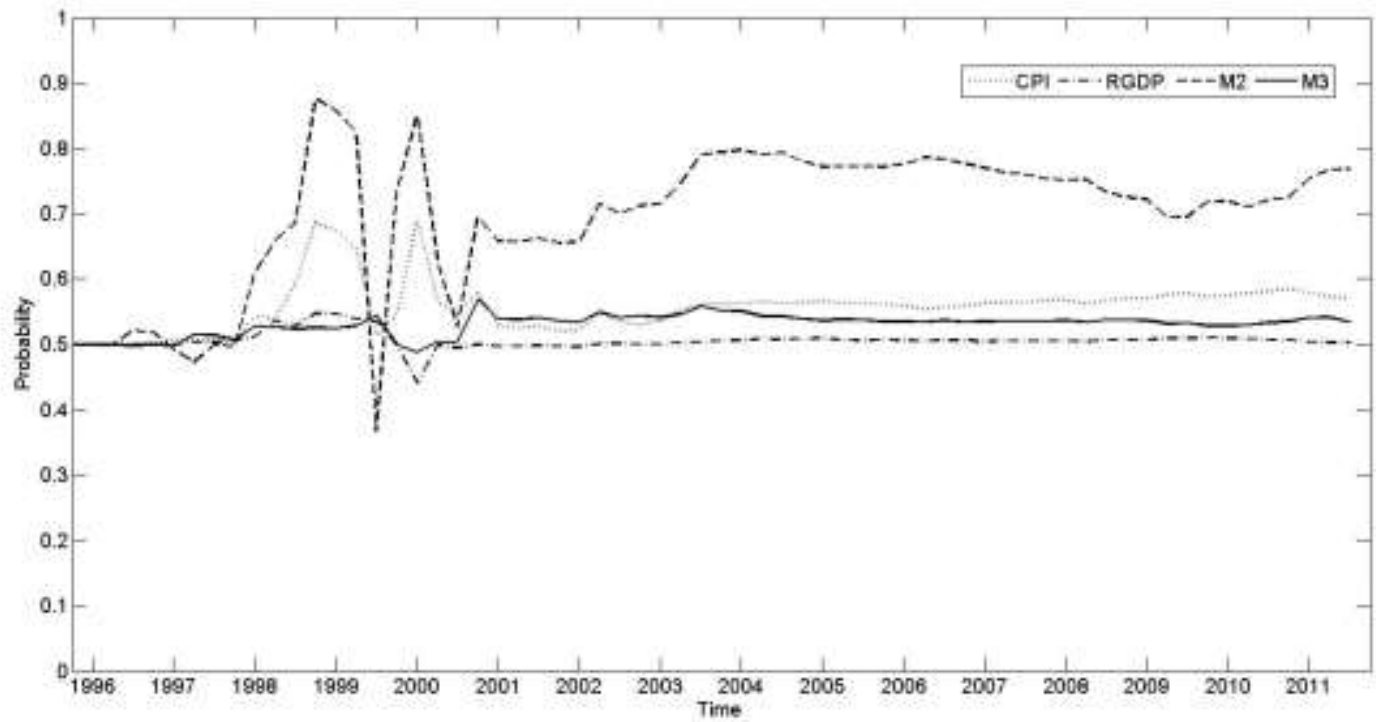

The results for the rand-pound exchange rate models (figures 7 through 10), are in line with that of the randdollar, with the most prominent variables selected for inclusion once again stock price differentials and commodity prices, in addition to the standard monetary model variables.

Over the 1-quarter-ahead forecast horizon we observe that for the rand-pound exchange rate, interest rate differentials, together with differences in money growth and the oil price, takes prominence as predictor variables over stock price differentials as is the case for the rand-dollar exchange rate over the 1-periodahead forecast horizon. Probabilities of inclusion of these variables take on high values in excess of 0.9 in the post 2000 period. In terms of the standard monetary model variables, even though the broad money differential only registered an average probability of inclusion of 0.48 , the inclusion probability for M2 money differential exceeds 0.7 for the most part of the post 2000 sample period and the growth in M1 
variable registered probability values of 0.9 and higher from 2001 onwards. In addition to the CPI inflation differential, the PPI inflation differential also seems to be an important predictor of exchange rate movements.

Figure 7: Rand-pound: posterior probability of inclusion of predictors, 1-quarter-ahead forecast $(d=1)$

(a)

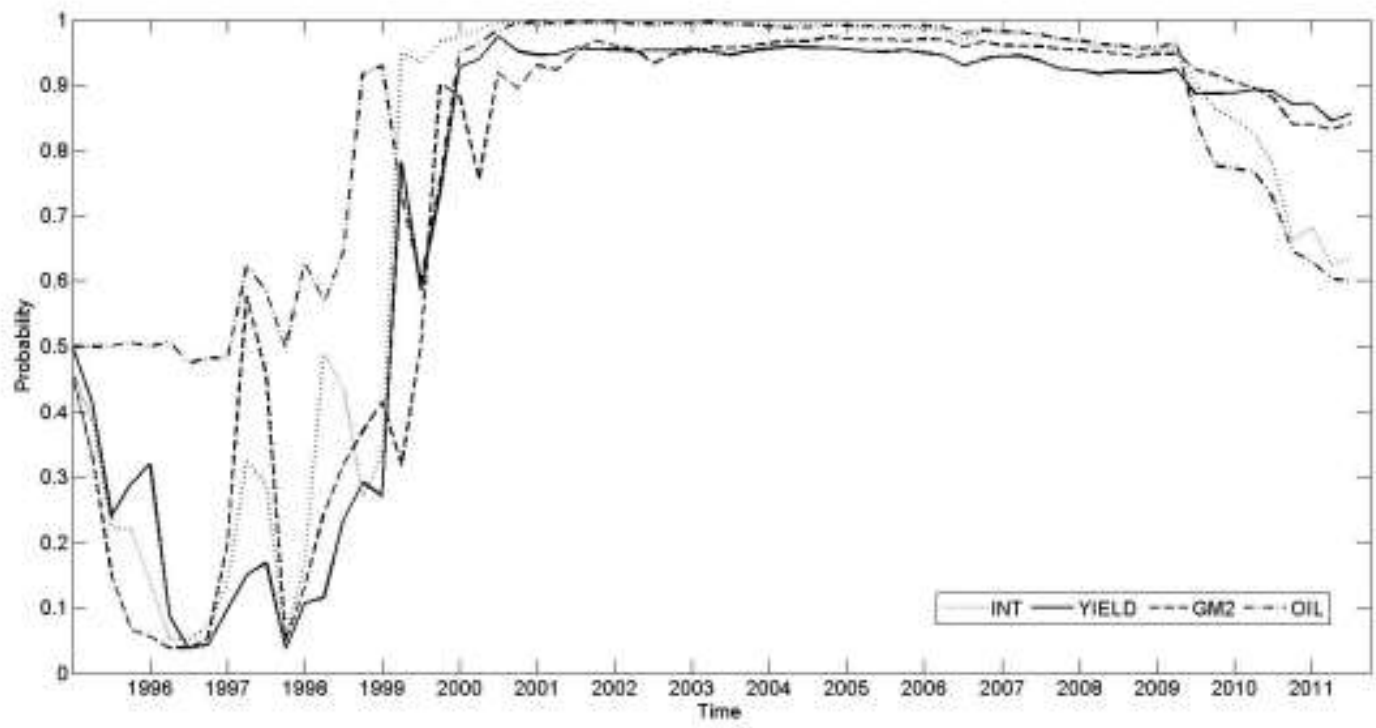

(b)

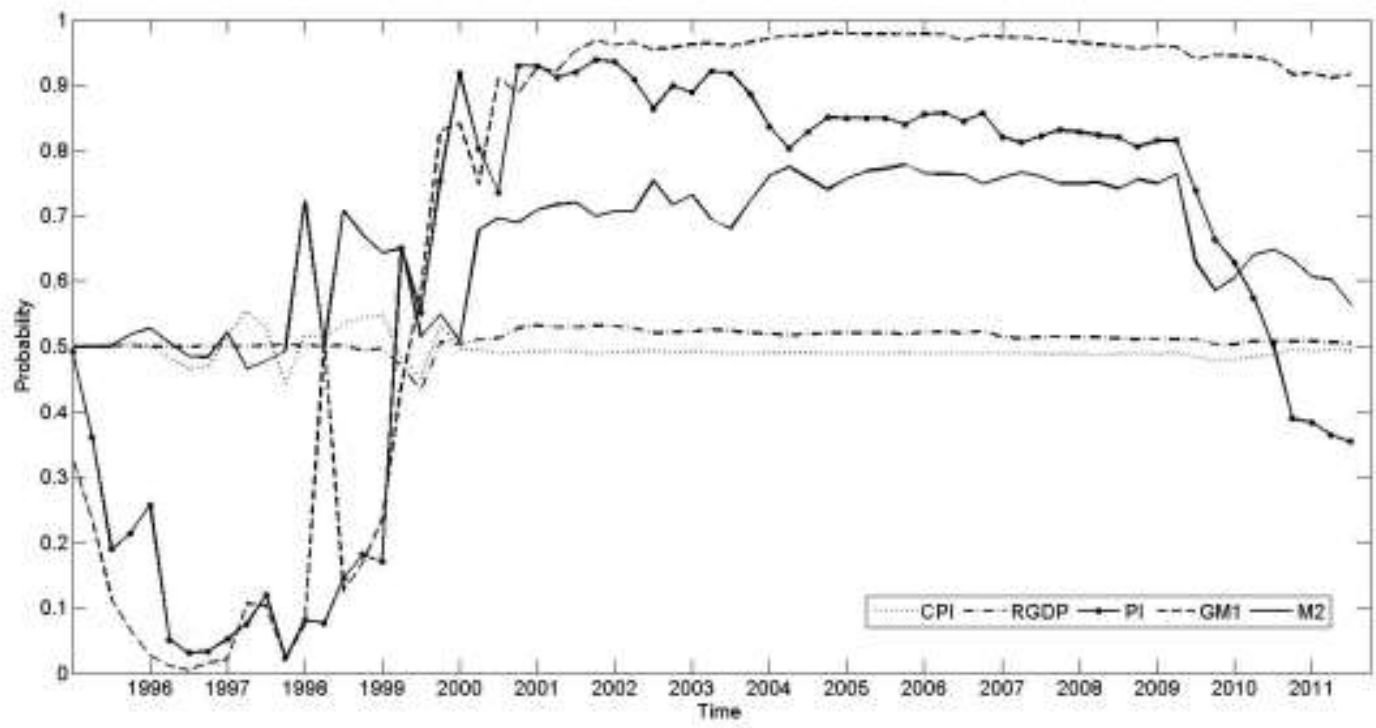

For the 2-quarter-ahead forecast horizon, all standard monetary model variables, as well as stock market and commodity prices appear in the list of selected predictors. In addition, we also see M1 and M2 money supply variables with average probabilities of inclusion in excess of 0.7 . The majority of variables registered high probabilities following 2000 with a decline towards the end of the out-of-sample period, whereas the real GDP and broad money differentials have lower but more stable inclusion probabilities. In times of uncertainty, like the global financial crisis of 2008, investors tend to buy gold as it is perceived as a safer alternative investment that will not be influenced by stock markets, which pushed the gold price to record 
highs. The high gold price may have caused gold to lose predictive ability towards the end of the sample in the rand-pound 2-quarter ahead forecast, as evident in figure 8.

Figure 8: Rand-Pound: posterior probability of inclusion of predictors, 2-quarter-ahead forecast $(d=2)$

(a)

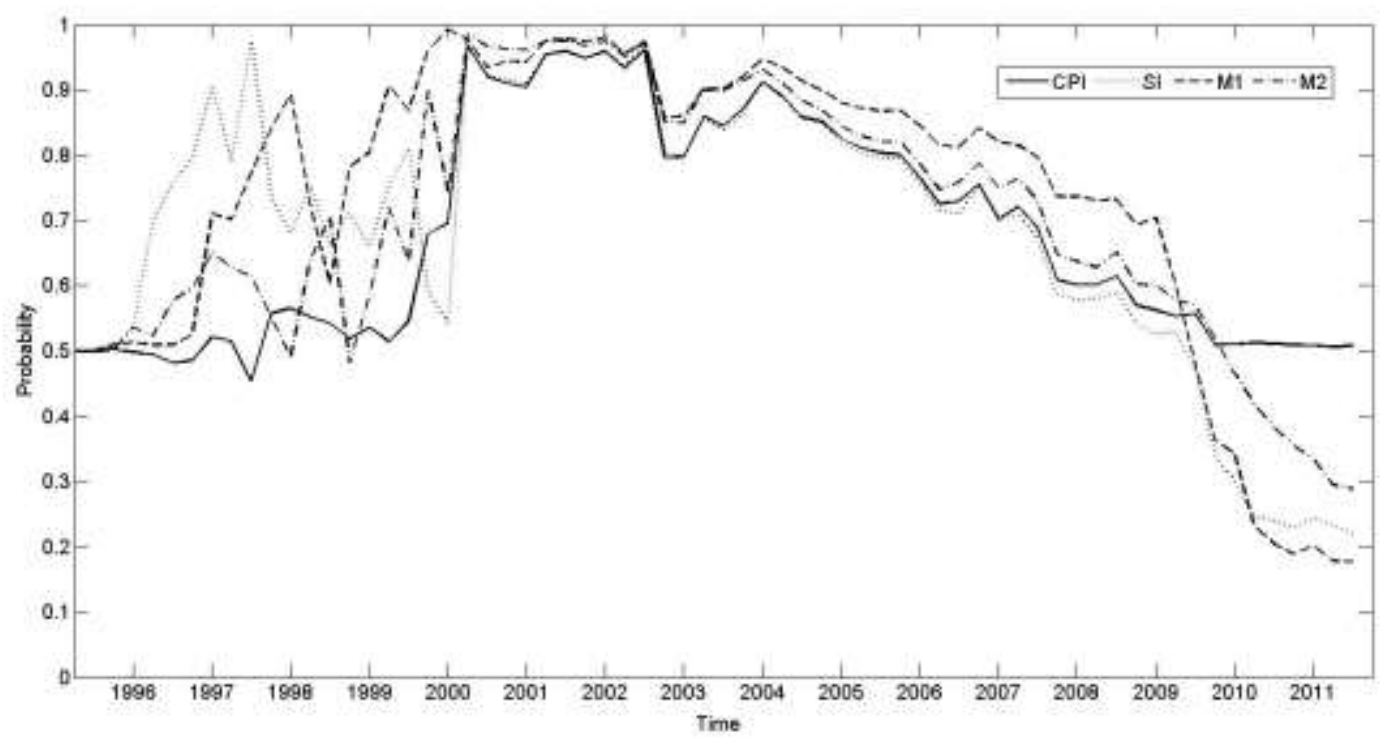

(b)

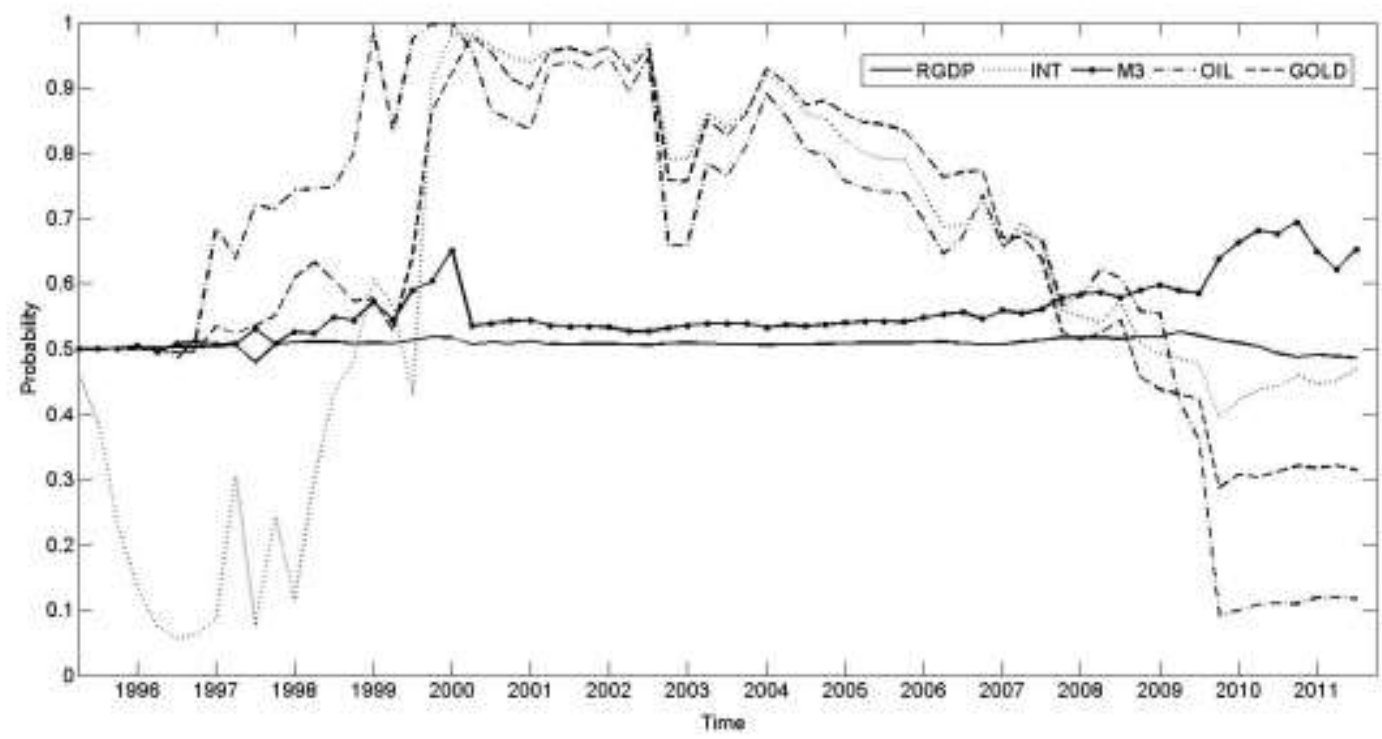

As we expand the forecasting horizon to 3-periods ahead, once again we note that differentials of all three money supply aggregates are selected for inclusion, in addition to the oil price and stock market price differential and other standard monetary model variables. Once again the predictive ability of the oil price declines towards the end of the sample. 
Figure 9: Rand-pound: posterior probability of inclusion of predictors, 3-quarter-ahead forecast $(d=3)$

(a)

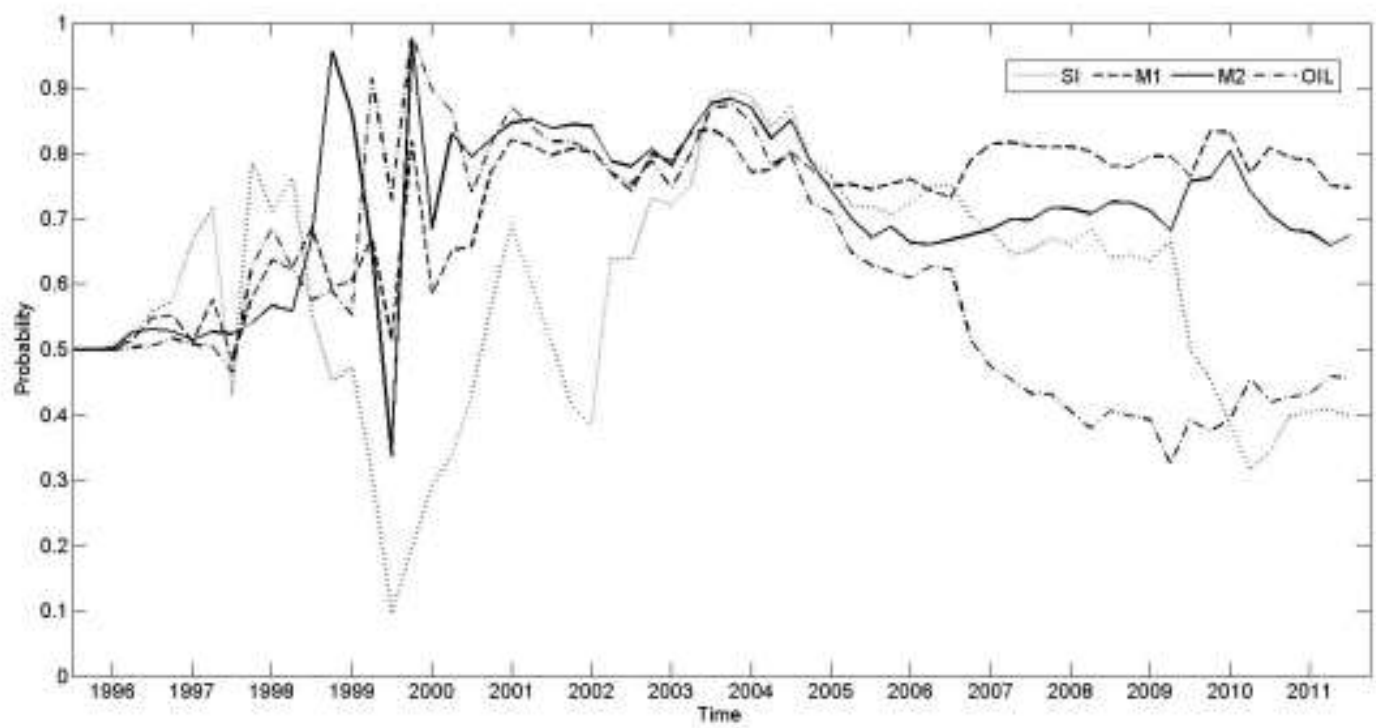

(b)

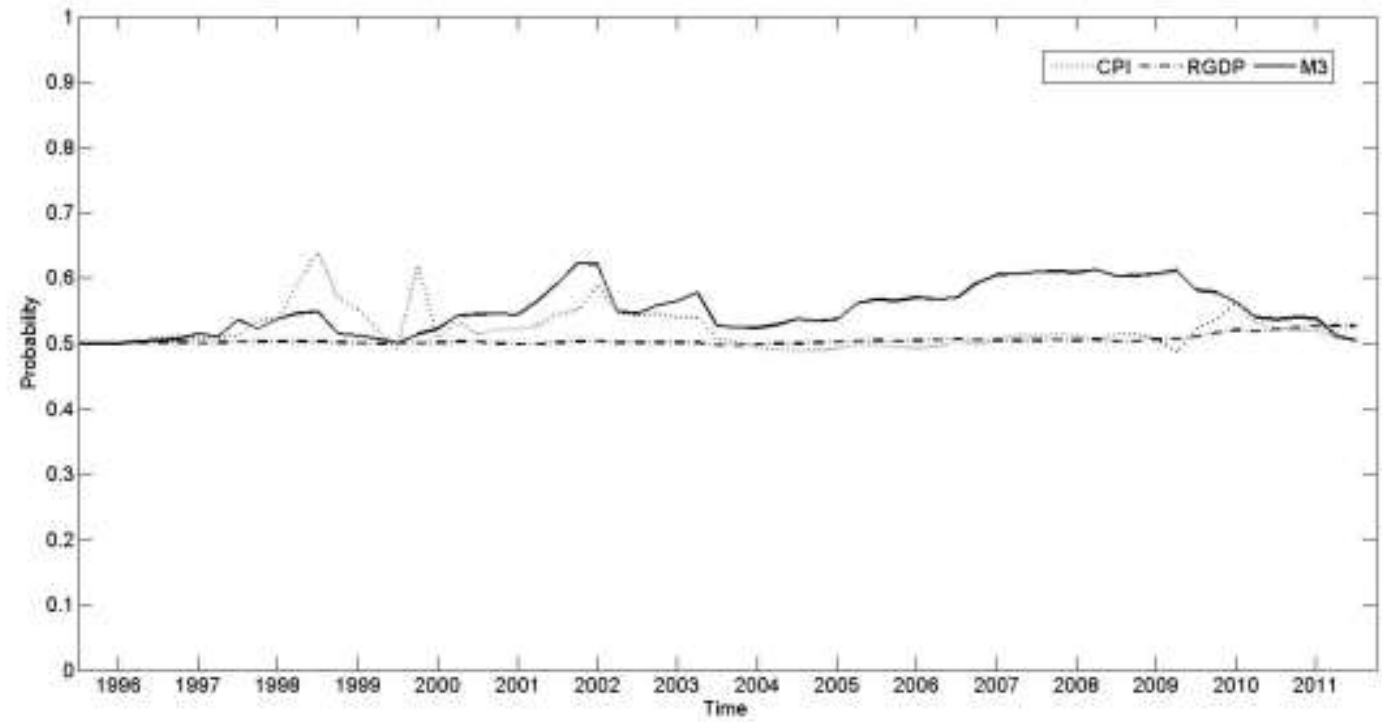

Finally, for the 4-period-ahead forecast horizon, the stock market price differential is a significant predictor variable with an inclusion probability of between 0.8 and 0.9 for the period 2000 to 2010. Both commodity prices are selected, although the gold price has a higher overall importance in explaining exchange rate behaviour. From the list of standard monetary model variables, the CPI inflation differential shows an increased probability of inclusion, that of 0.7 from 2007 onwards. 
Figure 10: Rand-pound: posterior probability of inclusion of predictors, 4-quarter-ahead forecast $(d=4)$

(a)

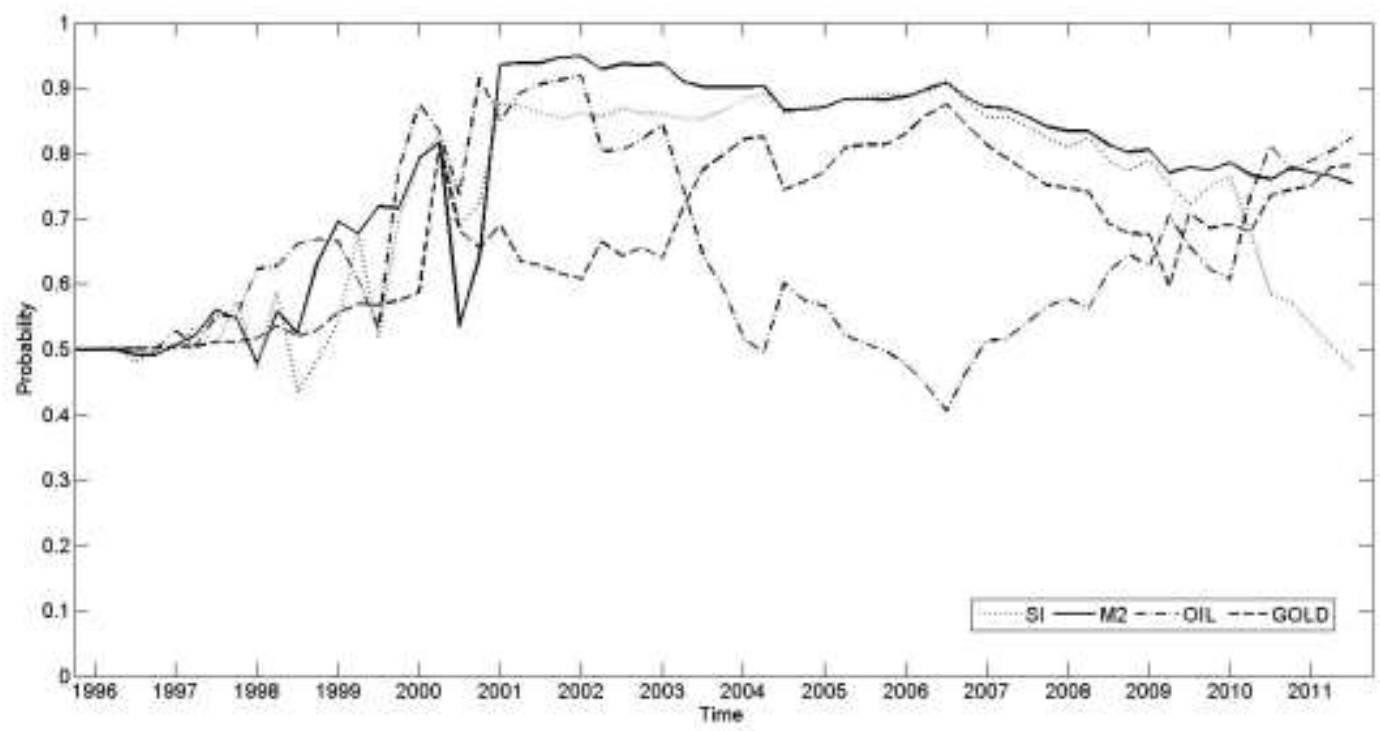

(b)

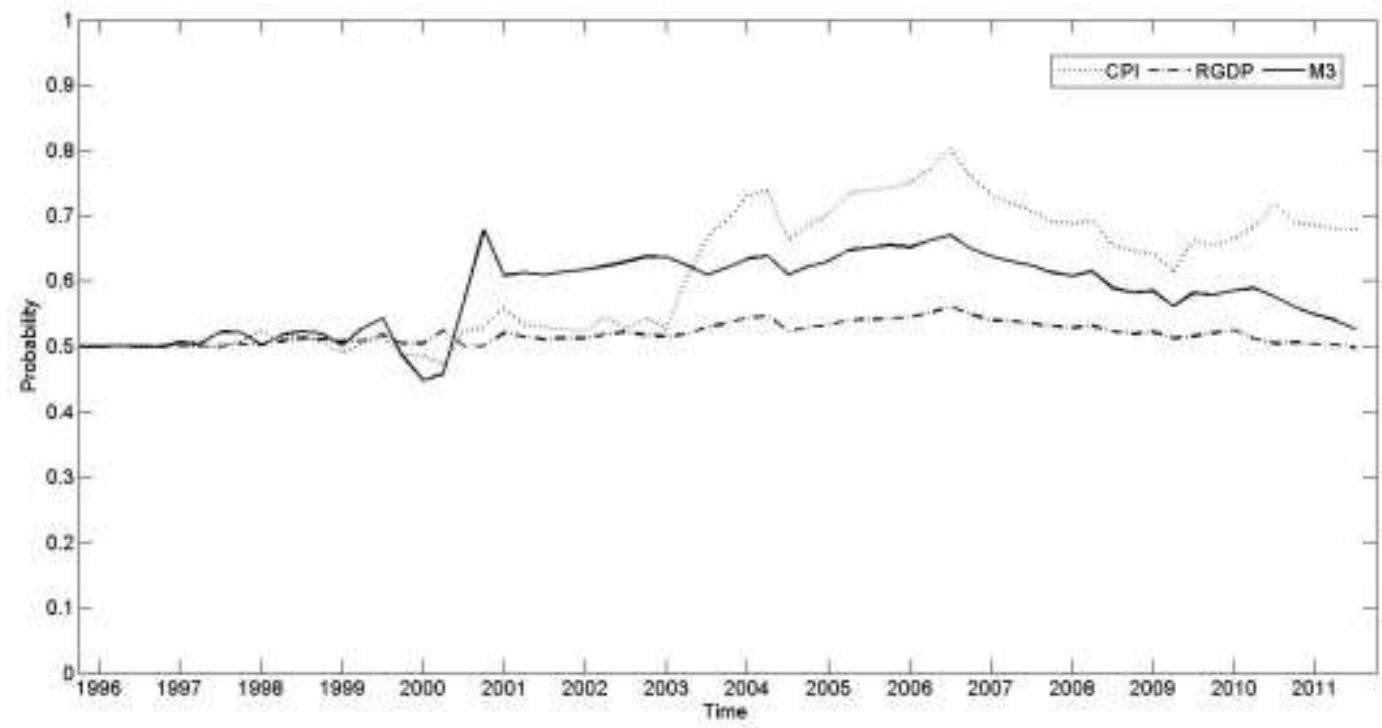

Imports and exports are highly dependent on exchange rates, therefore by including gold and oil prices as possible explanatory variables for both exchange rates it is not surprising to see that prices of both commodities are significant in exchange rate forecasting. The results show that oil price and gold price are selected for inclusion either together or separately in the models over all forecasting horizons. In addition to the more traditional variables included in exchange rate model specification, namely inflation, money supply, income and interest rate differentials, stock market activity also holds strong predictive power in terms of exchange rate forecasting.

It is worth noting that inclusion posterior probabilities for the "traditional" variables are consistently lower, but much more stable than stock market and commodity price variables for both models over all forecast horizons. This serves as indicator that fundamentals do drive long-run exchange rate behaviour, whereas 
commodity and stock market behaviour and events that impact these markets directly help to explain shortrun adjustments in the exchange rate. The key benefit using the DMA analysis is that the best predictors for the forecasting models are selected, taking the dynamics of the data into consideration.

\subsection{MODEL COMPARISONS}

To analyse the forecast performance of each model we use the mean squared forecast error (MSFE), which is available for all the models, including the random walk.

Note that, the preferred method for Bayesian forecast comparisons are the sum of the log predicted likelihood. The predictive likelihood is the predictive density for $y_{t}$, given data till $t$ - 1 , evaluated at the actual outcome. Since, we use the direct method of forecasting, the log predictive density for the $h$-step ahead forecast is an obvious extension of the formula for the one-step ahead predictive density in model $l$ as denoted by $p_{l}\left(y_{t} \mid y^{t-1}\right)$ and described in Section 2. We use the sum of log predictive likelihoods for forecast evaluation of the Bayesian models, with the sum beginning in the first quarter of 1995 up to the third quarter of 2011 of the out-of-sample period. MSFEs are obviously reported over the same period.

In terms of alternative forecasting models, the results for the following models are reported:

- $\quad$ Forecasts using DMA with $\alpha=\lambda=0.99$.

- $\quad$ Forecasts using DMS with $\alpha=\lambda=0.99$.

- Forecasts using all the variables in a single model with time varying parameters (100\% of the prior weight is attached to the model with all the variables in this special case of DMA, with all other modelling choices being identical including $\lambda=0.99$ ). These are the TVP results in the tables.

- Forecasts using DMA, but the coefficients do not vary over time (a special case of DMA where $\lambda=1$ and $\alpha=0.99)$.

- Forecasts using BMA (a special case of DMA where $\alpha=\lambda=1$ ).

- Forecasts using the random walk.

Only the last model is non-Bayesian, which means that there is no predictive likelihood for the random walk model.

From the results in table 1 for the rand-dollar exchange rate it is clear that DMA and DMS forecast generally well, with DMS being the best overall. The sum of the log predictive likelihood clearly shows that DMS performs better across all forecast horizons. This result also carries over to MSFE. Both the sum of the log 
predictive likelihood as well as the MSFE indicates that using a TVP model for forecasting results in poor forecasting performance on average. The only exception is for the 4-quarter-ahead forecast looking at the MSFE. This result is also only marginally better than that of the DMA model. In general, the results clearly show that by allowing for parameter as well as model dynamics improves the forecasting performance of the DMA and DMS models. It can therefore be concluded that allowing for model uncertainty and not just parameter uncertainty, improves the forecasting performance of these models.

Table 1: Comparing different forecasting methods: rand-dollar exchange rate

\begin{tabular}{|l|l|l|}
\hline \multicolumn{1}{|c|}{ FORECASTING METHOD } & \multicolumn{1}{c|}{ SUM OF LOG PRED. LIKE. } & \multicolumn{2}{c|}{ MSFE } \\
\hline DMA & $d=1$ & 53.0862 \\
\hline DMS & -227.9136 & 46.4872 \\
\hline TVP & -214.7371 & 53.7293 \\
\hline DMA $(\lambda=1)$ & -229.2343 & 52.8305 \\
\hline BMA (DMA with $\alpha=\lambda=1)$ & -227.7506 & 53.5687 \\
\hline Random Walk & -229.0775 & 59.5386 \\
\hline & & \\
\hline DMA & $d=2$ & 62.3378 \\
\hline DMS & -233.1787 & 55.8907 \\
\hline TVP & -226.2171 & 67.1270 \\
\hline DMA $(\lambda=1)$ & -234.8041 & 62.2512 \\
\hline BMA (DMA with $\alpha=\lambda=1)$ & -233.4454 & 66.8212 \\
\hline Random Walk & -234.7933 & 70.0487 \\
\hline & & \\
\hline DMA & $d=3$ & 62.4687 \\
\hline DMS & -222.7364 & 56.2985 \\
\hline TVP & -207.5583 & 63.5835 \\
\hline DMA $(\lambda=1)$ & -224.0766 & 62.8457 \\
\hline BMA (DMA with $\alpha=\lambda=1)$ & -222.7735 & 64.1143 \\
\hline Random Walk & -224.1199 & 68.5633 \\
\hline & & \\
\hline DMA & $d=4$ & 57.9128 \\
\hline DMS & -223.6936 & 53.0082 \\
\hline TVP & -214.3772 & 57.8125 \\
\hline DMA $(\lambda=1)$ & -224.0661 & 58.1319 \\
\hline BMA (DMA with $\alpha=\lambda=1)$ & -223.4143 & 58.0936 \\
\hline Random Walk & -223.7908 & 74.3548 \\
\hline & & - \\
\hline
\end{tabular}

The results for the rand-pound exchange rate, depicted in table 2, prove to be similar. The only real exception is that the random walk model is not the worst-performing model for the two and 3-quarter-ahead forecasts. Still the best models for forecasting the rand-pound exchange rate are the DMA and DMS models, with the DMS model being the overall best. It is clear from both table 1 and 2 that the DMA and DMS models are superior to the random walk model for forecasting purposes. 
Table 2: Comparing different forecasting methods: rand-pound exchange rate

\begin{tabular}{|c|c|c|}
\hline FORECASTING METHOD & SUM OF LOG PRED. LIKE. & MSFE \\
\hline & \multicolumn{2}{|l|}{$d=1$} \\
\hline DMA & -215.8170 & 34.9379 \\
\hline DMS & -207.9691 & 25.1212 \\
\hline TVP & -216.4676 & 35.2428 \\
\hline $\operatorname{DMA}(\lambda=1)$ & -215.7112 & 34.6773 \\
\hline BMA (DMA with $\alpha=\lambda=1$ ) & -216.2926 & 34.9072 \\
\hline \multirow[t]{2}{*}{ Random Walk } & - & 45.0796 \\
\hline & \multicolumn{2}{|l|}{$d=2$} \\
\hline DMA & -224.6565 & 44.5606 \\
\hline DMS & -220.6167 & 43.2199 \\
\hline TVP & -226.5062 & 46.5341 \\
\hline $\operatorname{DMA}(\lambda=1)$ & -215.9831 & 53.8871 \\
\hline BMA (DMA with $\alpha=\lambda=1$ ) & -228.1503 & 46.8310 \\
\hline \multirow[t]{2}{*}{ Random Walk } & - & 49.9424 \\
\hline & \multicolumn{2}{|l|}{$d=3$} \\
\hline DMA & -215.4151 & 50.5509 \\
\hline DMS & -203.1042 & 45.6382 \\
\hline TVP & -216.9861 & 53.2513 \\
\hline $\operatorname{DMA}(\lambda=1)$ & -214.6949 & 50.3987 \\
\hline BMA (DMA with $\alpha=\lambda=1$ ) & -216.3292 & 53.0459 \\
\hline \multirow[t]{2}{*}{ Random Walk } & - & 51.0070 \\
\hline & \multicolumn{2}{|l|}{$d=4$} \\
\hline DMA & -220.0699 & 45.0891 \\
\hline DMS & -209.5796 & 40.7073 \\
\hline TVP & -221.3141 & 46.0816 \\
\hline DMA $(\lambda=1)$ & -220.2210 & 45.1594 \\
\hline BMA (DMA with $\alpha=\lambda=1$ ) & -221.5368 & 46.1681 \\
\hline Random Walk & 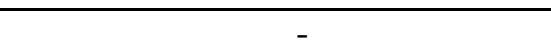 & 55.4387 \\
\hline
\end{tabular}

\section{CONCLUSION}

In this paper we use DMA techniques to forecast the rand-dollar and rand-pound exchange rates over a short horizon (one to four quarters) using macroeconomic variables.

Exchange rates are very sensitive to speculation and external shocks which tend to cause forecasts to be incorrect. Because of speculation in the foreign exchange market, estimating an accurate model is very difficult. DMA has provided an easier alternative to account for the uncertainty in the market. Using DMA analysis which allows for parameter and model evolution over time we show that model uncertainty is as important as parameter uncertainty, especially when working with noisy data such as exchange rate data. 
Volatility in exchange rate data can be more accurately captured through the constant updating process in the DMA models. The results show that using DMA leads to generally improved forecasting performance.

With the choice of the set of predictors used at each point in time left to the DMA analysis, these models have increased forecasting performance when compared to that of the random walk model. In the process, we also identify variables, which tends to vary over time, that are good predictors of the rand-dollar and rand -pound exchange rates at different forecast horizons. More importantly, using South Africa as a case study, we show that DMA models perform better than BMA models, which in turn, are used traditionally to account for parameter uncertainty in the forecasting literature on exchange rates involving many potential predictors. Our results highlight the importance of accounting for model uncertainty over and above parameter uncertainty.

\section{LIST OF REFERENCES}

Alpanda, S., Kotzé, K. \& Woglom, G. 2011. Forecasting performance of an estimated DSGE model for the South African Economy. South African Journal of Economics, 79(1):50-67.

Bonga-Bonga, L. 2008. Modelling the Rand-Dollar Future Spot Rates: The Kalman Filter Approach. The African Finance Journal, , 10(2):60-75.

Bonga-Bonga, L. 2009. Forward Exchange Rate Puzzle: Joining the Missing Pieces in the Rand-US Dollar Exchange Market. Working Papers 122, Economic Research Southern Africa.

Botha, I. \& Pretorius, M. 2009. Forecasting the exchange rate in South Africa: a comparative analysis challenging the random walk model. African Journal of Business Management, 9(3):486-494.

Coleman, S., Cuestas, J.C. \& Mourelle, E. 2011. Investigating the oil price-exchange rate nexus: evidence from Africa. Sheffield Economic Research Paper Series, 2011015:1-38.

de Bruyn, R., Gupta, R. \& Stander, L. forthcoming. Testing the monetary model for exchange rate determination in South Africa: evidence from 101 years of data. Contemporary Economics.

de Jager, S. 2012. Modelling South Africa's equilibrium real effective exchange rate: a VECM approach. South African Reserve Bank Working Paper, WP/12/02:1-23. 
Dua, P. \& Ranjan, R. 2011. Modelling and Forecasting the Indian RE/Dollar exchange Rate. Centre for development Economics, Working Paper No. 197.

Feldkircher, M. 2008. Forecast combination and Bayesian model averaging. Seminar Paper Version 1.4.

Gupta, R. \& Kabundi, A. 2010. Forecasting Macroeconomic Variables in a Small Open Economy: A Comparison between Small- and Large-Scale Models. Journal of Forecasting, 29, (1-2):168-185.

Gyntelberg, J., Loretan, M., Subhanij, T. \& Chan, E. 2009. Private information, stock markets, and exchange rates. BIS Working Papers, 271:1-26.

Hooper, P. \& Morton, J. 1982. Fluctuations in the Dollar: A Model of Nominal and Real Exchange Rate Determination. Journal of International Money and Finance, 1:39-56.

Koop, G. \& Korobilis, D. 2012. Forecasting inflation using dynamic model averaging. International Economic Review, 53:867-886.

Mtonga, E. 2011. Did it matter? Monetary Policy Regime Change and Exchange Rate Dynamics in South Africa. Oxford University Centre for the Study of African Economies, 1-62.

Raftery, A.E., Kárný, M. \& Ettler, P. 2010. Online prediction under model uncertainty via dynamic model averaging: application to a cold rolling mill. Technometrics, 52(1):52-66.

Throop, A.W., Laderman, E.S. \& Walsh, C.E. 1993. A Generalized Uncovered Interest Parity Model of Exchange Rates. Economic Review: Federal Reserve Bank of San Francisco, 1993(2):3-16.

Tortora, A.D. 2009. Exchange rate forecasting: Bayesian model averaging and structural instability. December 2009. Available from: http://www.ucl.eu/cps/ucl/doc/core/ documents/tortora.pdf.

Wright, J.H. 2008. Bayesian model averaging and exchange rate forecasts. Journal of Econometrics, 146:329-341.

Zita, S. \& Gupta, R. 2008. Modelling and Forecasting the Metical-Rand Exchange Rate. ICFAI Journal of Monetary Economics, 4: 63-90. 


\section{DATA APPENDIX}

The $z_{i, t}$ variables are all transformed to be approximately stationary according to the following codes: $1-$ No transformation (levels), $x_{i, t}=z_{i, t} ; 2$ - First difference; $x_{i, t}=z_{i, t}-z_{i, t-1} ; 3$ - Logarithm, $x_{i, t}=\log z_{i, t} ; 4-$ First difference of the logarithm; $x_{i, t}=\log z_{i, t}-\log z_{i, t-1}$ (Koop \& Korobilis, 2012).

Table 3: Rand-dollar exchange rate variables

\begin{tabular}{|c|c|c|c|}
\hline VARIABLE & TCODE & DESCRIPTION $\left(z_{i, t}\right)$ & SOURCE \\
\hline USDZAR & 4 & Rand/US\$ market exchange rate. & $\begin{array}{l}\text { Global Financial } \\
\text { Database }\end{array}$ \\
\hline LZALUS_CPI & 2 & $\begin{array}{l}\text { Log SA consumer price index minus log US } \\
\text { consumer price index (base }=2005 \text { ). }\end{array}$ & $\begin{array}{l}\text { Global Financial } \\
\text { Database }\end{array}$ \\
\hline LZALUS_RGDP & 2 & $\begin{array}{l}\text { Log SA real GDP minus log US real GDP } \\
\text { (base=2005). }\end{array}$ & $\begin{array}{l}\text { Global Financial } \\
\text { Database }\end{array}$ \\
\hline ZAUS_PI & 2 & $\begin{array}{l}\text { Annual SA inflation rate minus annual US } \\
\text { inflation rate (calculated). }\end{array}$ & $\begin{array}{l}\text { Global Financial } \\
\text { Database }\end{array}$ \\
\hline LZALUS_SI & 2 & $\begin{array}{l}\text { Log FTSE/JSE All-share index minus log NYSE } \\
\text { composite index. }\end{array}$ & $\begin{array}{l}\text { Global Financial } \\
\text { Database }\end{array}$ \\
\hline ZAUS_CGDP & 2 & $\begin{array}{l}\text { SA current account balance as a ratio of GDP } \\
\text { minus US current account balance as a ratio of } \\
\text { GDP. }\end{array}$ & IFS, IMF \\
\hline ZAUS_INT & 1 & $\begin{array}{l}\text { 3-month SA treasury bill yield minus CBOE 13- } \\
\text { week US treasury bill yield. }\end{array}$ & $\begin{array}{l}\text { Global Financial } \\
\text { Database }\end{array}$ \\
\hline ZAUS_YIELD & 2 & $\begin{array}{l}\text { SA 10-year government bond yield minus US } \\
10 \text {-year bond constant maturity yield. }\end{array}$ & $\begin{array}{l}\text { Global Financial } \\
\text { Database }\end{array}$ \\
\hline LZALUS_M1 & 2 & $\begin{array}{l}\text { Log SA M1 money supply minus log US M1 } \\
\text { money supply. }\end{array}$ & $\begin{array}{l}\text { Global Financial } \\
\text { Database }\end{array}$ \\
\hline ZAUS_GM1 & 1 & Growth in SA M1 minus growth in US M1. & Calculated \\
\hline LZALUS_M2 & 2 & $\begin{array}{l}\text { Log SA M2 money supply minus log US M2 } \\
\text { money supply. }\end{array}$ & $\begin{array}{l}\text { Global Financial } \\
\text { Database }\end{array}$ \\
\hline ZAUS_GM2 & 1 & Growth in SA M2 minus growth in US M2. & Calculated \\
\hline LZALUS_M3 & 2 & $\begin{array}{l}\text { Log SA M3 money supply minus log US M3 } \\
\text { money supply. }\end{array}$ & $\begin{array}{l}\text { Global Financial } \\
\text { Database }\end{array}$ \\
\hline ZAUS_GM3 & 1 & Growth in SA M3 minus growth in US M3. & Calculated \\
\hline LOIL & 2 & $\begin{array}{l}\text { Log of the brent crude oil price in US\$ per } \\
\text { barrel. }\end{array}$ & $\begin{array}{l}\text { Global Financial } \\
\text { Database }\end{array}$ \\
\hline LGOLD & 2 & $\begin{array}{l}\text { Log of the gold spot price - London PM fixing } \\
\text { (US\$/ounce). }\end{array}$ & $\begin{array}{l}\text { Global Financial } \\
\text { Database }\end{array}$ \\
\hline
\end{tabular}


Table 4: Rand-pound exchange rate variables

\begin{tabular}{|c|c|c|c|}
\hline VARIABLE & TCODE & DESCRIPTION, $\left(z_{i, t}\right)$ & SOURCE \\
\hline GBPZAR & 4 & $\begin{array}{l}\text { Rand/UK£ market exchange rate from the } \\
\text { US\$/R \& US\$/UK£ exchange rates. }\end{array}$ & $\begin{array}{l}\text { Global Financial } \\
\text { Database }\end{array}$ \\
\hline LZALUK_CPI & 2 & $\begin{array}{l}\text { Log SA consumer price index minus } \log \mathrm{UK} \\
\text { retail price index (base=2005). }\end{array}$ & $\begin{array}{l}\text { Global Financial } \\
\text { Database }\end{array}$ \\
\hline LZALUK_RGDP & 2 & $\begin{array}{l}\text { Log SA real GDP minus log UK real GDP } \\
\text { (base=2005). }\end{array}$ & $\begin{array}{l}\text { Global Financial } \\
\text { Database }\end{array}$ \\
\hline ZAUK_PI & 2 & $\begin{array}{l}\text { Annual SA inflation rate minus annual UK } \\
\text { inflation rate (calculated). }\end{array}$ & $\begin{array}{l}\text { Global Financial } \\
\text { Database }\end{array}$ \\
\hline LZALUK_SI & 2 & $\begin{array}{l}\text { Log FTSE/JSE All-share index minus log UK } \\
\text { FTSE All-share index. }\end{array}$ & $\begin{array}{l}\text { Global Financial } \\
\text { Database }\end{array}$ \\
\hline ZAUK_CGDP & 2 & $\begin{array}{l}\text { SA current account balance as a ratio of GDP } \\
\text { minus UK current account balance as a ratio of } \\
\text { GDP. }\end{array}$ & IFS, IMF \\
\hline ZAUK_INT & 1 & $\begin{array}{l}\text { 3-month SA treasury bill yield minus UK 3- } \\
\text { month treasury bill yield. }\end{array}$ & $\begin{array}{l}\text { Global Financial } \\
\text { Database }\end{array}$ \\
\hline ZAUK_YIELD & 2 & $\begin{array}{l}\text { SA 10-year government bond yield minus UK } \\
\text { 10-year government bond yield. }\end{array}$ & $\begin{array}{l}\text { Global Financial } \\
\text { Database }\end{array}$ \\
\hline LZALUK_M1 & 2 & $\begin{array}{l}\text { Log SA M1 money supply minus log UK M1 } \\
\text { money supply. }\end{array}$ & $\begin{array}{l}\text { Global Financial } \\
\text { Database }\end{array}$ \\
\hline ZAUK_GM1 & 1 & Growth in SA M1 minus growth in UK M1. & Calculated \\
\hline LZALUK_M2 & 2 & $\begin{array}{l}\text { Log SA M2 money supply minus log UK M2 } \\
\text { money supply. }\end{array}$ & $\begin{array}{l}\text { Global Financial } \\
\text { Database }\end{array}$ \\
\hline ZAUK_GM2 & 1 & Growth in SA M2 minus growth in UK M2. & Calculated \\
\hline LZALUK_M3 & 2 & $\begin{array}{l}\text { Log SA M3 money supply minus log UK M3 } \\
\text { money supply. }\end{array}$ & $\begin{array}{l}\text { Global Financial } \\
\text { Database }\end{array}$ \\
\hline ZAUK_GM3 & 1 & Growth in SA M3 minus growth in UK M3. & Calculated \\
\hline LOIL & 2 & $\begin{array}{l}\text { Log of the brent crude oil price in US\$ per } \\
\text { barrel. }\end{array}$ & $\begin{array}{l}\text { Global Financial } \\
\text { Database }\end{array}$ \\
\hline LGOLD & 2 & $\begin{array}{l}\text { Log of the gold spot price - London PM fixing } \\
\text { (US\$/ounce). }\end{array}$ & $\begin{array}{l}\text { Global Financial } \\
\text { Database }\end{array}$ \\
\hline
\end{tabular}

